\title{
The Ideological and Religious Bases of Attitudes Toward Pope Francis in the United States
}

\author{
Christopher M. Federico \\ Departments of Political Science and Psychology \\ University of Minnesota
}

\begin{abstract}
Since his election in 2013, Pope Francis has achieved influence as a religious leader while also impacting political discussions through his teachings on social justice and environmental matters. In the United States, his teachings on these topics have generated some controversy among right-leaning figures. In the present study, I look at whether this controversy is reflected in mass opinion about Pope Francis. Using data from three national surveys of Americans, I find that individuals who identify with the political right evaluate Francis more negatively. Qualifying this, Catholic religious affiliation weakens the tendency for right-wing identifiers to evaluate Francis more negatively, while strengthening the tendency for those high in religiosity to evaluate the pope positively. Finally, consistent with the idea that politically-aware individuals are more likely to make ideologically-informed judgments, the relationship between identification with the political right and negative evaluations of Pope Francis was stronger among the politically engaged.

Keywords: ideology, political awareness, Pope Francis, Roman Catholicism, religiosity
\end{abstract}

\section{IN PRESS, Journal for the Scientific Study of Religion}

* Correspondence should be addressed to Christopher M. Federico, Department of Political Science, 1414 Social Sciences Building, 267 19th Ave S, Minneapolis, MN 55455. Phone: (612) 6257217. E-mail: federico@umn.edu. All data and code for replication can be found at https://osf.io/jtw95/. 
Elected in the wake of Pope Benedict XVI's unexpected abdication of the papacy in 2013, Pope Francis has made an impression not only as the leader of the Roman Catholic Church, but also as a global moral authority of increasing significance. Most notably, he has emerged as a prominent critic of inequality, economic injustice, and environmental degredation. He has often returned to these themes in public sermons and speeches, and he has argued passionately for the moral importance of economic justice and environmental concern to Christian morality as a matter of authoritaritative teaching in the encyclical letters Laudato si' (2015) and Fratelli tutti (2020). Francis's teachings in this regard, rather than being innovations, are in continuity with a longer tradition of Catholic social teaching. In this regard, his concerns about global inequality and the importance of environmental stewardship echo those raised by his predecessors in older teaching documents, such as Pope Paul VI's Octogesima adveniens (1971), Pope John Paul II's Sollictudo rei socialis (1987), and Pope Benedict XVI's Caritas en veritate (2009).

The prominence of Pope Francis's social concerns have led many commentators both inside and outside the Catholic Church to code him as an especially "liberal" or "leftist" figure (Neumayr 2017). This characterization is imprecise in a number of ways, given the aforementioned continuity between Francis's social teaching and that of his more-conservative predecessors, the extent to which his thought incorporates themes shared with traditional conservative critiques of modernity (e.g., Ivereigh 2019), and the fact that he holds a number of socially-conservative positions that are a standard part of Catholic teaching (e.g., opposition to abortion and euthanasia; see Brekke 2015). That said, the impression of Francis as a liberal or left-leaning figure has been furthered by the reception of his social teaching in the broader public sphere, especially in the United States. On one hand, his sharp criticisms of inequality and environmental indifference have been strongly praised by figures on the left such as Senator Bernie Sanders (e.g., Green 2015). On the other hand, and perhaps even more loudly, conservative opinion leaders have criticized Pope Francis as naïve and 
radical (Robbins 2015). For example, on the occasion of his 2015 pastoral visit to the United States, right-wing talk-radio host Michael Savage referred to Francis as a "stealth Marxist in religious garb," while Fox News analyst Andrew Napolitano opined that Francis sounded "like a left-wing professor at the London School of Economics" (Willis 2015).

Though the responses of politicians and pundits to Pope Francis's public teaching have received much attention, researchers have not devoted much attention to whether a similar ideological divide in impressions of the pontiff can be found in mass opinion. In the present study, I fill this gap by examining the ideological and religious predictors of attitudes toward Pope Francis in the American public. I argue that Americans who identify with the right should evaluate Francis more negatively. However, I also argue that Catholic affiliation should weaken this tendency, while simultaneously strengthening the relationship between religiosity and positive views of Francis. Finally, in line with research suggesting that ideology more strongly influences opinion formation among the politically-aware, I argue that the relationship between ideology and evaluations of the pope should be stronger among those high in political engagement.

\section{Ideology, Religion, and Evaluations of Pope Francis}

As noted above, the differing public reactions to Pope Francis's teaching in the United States suggests that views of Pope Francis himself may be ideologically polarized in the mass public as well. Specifically, several general lines of research in political behavior lead to the expectation that individuals who identify with the political right should evaluate Francis more negatively. Individuals on the right are less positively disposed to criticisms of inequality of the sort that Francis has offered in his social teaching (Jost 2020; Jost, Glaser, Kruglanski, and Sulloway, 2003; Jost, Federico, and Napier 2009, 2013). In particular, right-wing identifiers in English-speaking nations like the United States (relative to other parts of the world) are especially committed to the market-oriented individualism criticized by Francis (Federico and Malka 2018; Malka, Lelkes, and Soto 2019; see also 
Azevedo, Jost, Rothmund, and Sterling 2019; Johnston, Lavine, and Federico 2017). In the United States, left and right identifiers are also sharply polarized on climate change, another issue central to Francis' social teaching. As a great deal of research suggests, American conservatives are more likely to doubt the seriousness of climate change and less likely to support efforts to mitigate it, potentially placing them in greater opposition than moderates and liberals to Francis's position (Kahan et al. 2012; McRight et al. 2014, 2016; Schwom et al. 2015).

These basic ideological differences are also reinforced by disparate top-down signals from political elites. As noted earlier, despite commonalities between his social teaching and that of his predecessors, Pope Francis has come in for especially strong criticism from conservative and Republican opinion leaders, including many right-leaning Catholics (Robbins 2015). Liberal and conservative political elites in the United States have also sent very different signals about the importance of Francis's signature social concern, climate change (contributing to the broader polarization on this issue described above; Jacques, Dunlap, and Freeman 2008). Given the role of of elite disagreement in eliciting polarization as the mass level (see Converse 1964; Levendusky 2009; Zaller 1992), these patterns further suggest that evaluations of Pope Francis should be ideologically polarized in the American context.

At the same time, there are likely to be important moderators of any relationship between ideology and attitudes toward Pope Francis. Above all, denominational identity may be a crucial boundary condition on ideological polarization in evaluations of Francis. Insofar as Pope Francis and the papacy in general are authoritative symbols of the unity of the Catholic Church, even politically conservative Catholics who are inclined to disagree with Francis's social teachings may continue to respect him. Here, Catholic social identity may overwhelm ideology as a motivation. Individuals are generally motivated to favor and defend important group identities (e.g., Tajfel and Turner 1986), and religion is an especially important and self-relevant identity in this regard 
(Ysseldyk, Matheson, and Anisman 2010; Norenzayan 2014). Defense of an important social identity also entails respect for group leaders and important group symbols (Hogg 2005; Hogg and van Knippenberg 2003), potentially inoculating Francis against ideological animus to a greater extent among Catholics. For this reason, the relationship between right-wing identification and negative evaluations of Francis is likely to be weaker among Catholics.

The logic of social identity also suggests that a weaker relationship between ideology and Francis evaluations may be accompanied by a stronger relationship between individual differences in religiosity and evaluations of the pope among Catholics. Here, I define religiosity in the sense of greater behavioral and attitudinal commitment to religion in one's life (Malka 2013; Smidt et al. 2009). All things considered, greater religious commitment among Catholics should predict more positive evaluations of Pope Francis, since social identity concerns should presumably be more engaged among religiously-involved Catholics (Ysseldyk et al. 2010). In contrast, religiosity should be less central to evaluations of Francis among non-Catholics, since the papacy should be less identity-relevant outside the Catholic faith.

In contrast, other factors may strengthen the relationship between ideology and evaluations of the pope in the American context. As much research suggests, ideology plays a more important role in political judgment among those who are politically engaged, i.e.., informed about and interested in politics (Converse 1964; Federico and Malka 2018; Kinder and Kalmoe 2017; Zaller 1992). Politically-engaged citizens are more likely to understand the symbolic and programmatic differences between left-wing and right-wing ideological positions and more likely to receive cues from political elites about which attitudes toward various political objects are consistent with a given ideology (Kinder and Kalmoe 2017). They are also more likely to care about adopting positions that publicly express their underlying political identifications with the left or the right (Federico and Ekstrom 2018; Johnston et al. 2017). Thus, to the extent that evaluations of Pope Francis now have an 
ideological component, ideological disagreement about Francis should be stronger among the politically engaged and the tendency for those who identify with the right to evaluate Francis more negatively should be more pronounced among those high in engagement.

\section{Extant Research}

In the academic literature, these questions have received fairly little examination. Given his attention to the topic in the encyclical Laudato si' and elsewhere, much of the research on the political significance of Pope Francis and his teachings has centered specifically on attitudes and beliefs regarding climate change (see Landrum and Vasquez 2020, for a review). This literature provides some evidence that exposure to Francis's teachings on the environment increases the extent to which individuals see the climate-change issue in moral terms (Schuldt, Pearson, RomeroCanyas, and Larson-Konar 2017; Shin and Preston 2019) and feel responsibility for combating climate change (Schuldt et al. 2017). However, it also finds that effects of exposure to Francis's teachings are limited to those already concerned about climate change (Myers, Roser-Renouf, Maibach, and Leiserowitz 2017) and Democrats (Schuldt et al. 2017). More directly consistent with the idea that responses to Francis are ideologically stratified, other work finds that awareness of Laudato si' polarizes climate-change attitudes as a function of ideological self-placement (Li, Hilgard,

Scheufele, Winneg, and Jamieson 2016) and reduces the perceived credibility of Pope Francis among conservative identifiers even if they are Catholic (Li et al. 2016; see also Landrum, Lull, Akin, Hasell, and Jamieson 2017; Landrum and Vasquez 2020).

A handful of analyses have more directly examined the questions the present study focuses on. In the wake of the pope's 2015 visit to the United States, the Pew Research Center (2015) found 
somewhat higher approval of Francis among liberals and among Democrats. ${ }^{1}$ Follow-up analyses in 2018 found a similar pattern with respect to partisanship, and also found that Catholics who attended services more frequently approved more of Pope Francis (Pew Research Center 2018; see also Nortey and Gecewicz 2020). Though these results are instructive, they do not adequately address many of the questions raised above. In particular, they do not independently examine the effects of ideology and partisanship. Nor do they examine the ways in which the relationships between ideology and religiosity (on one hand) and evaluations of Pope Francis (on the other) differ as a function of Catholic affiliation. Finally, they do not address the question of whether politicallyengaged individuals are better able to bring their ideological identifications to bear on their evaluations of Francis.

\section{Overview}

In the present study, I fill these gaps by examining the intersecting ways in which evaluations of Pope Francis vary as a function of ideology, religious affiliation, and religiosity. To do so, I turn to data from three nationally-representative surveys of American adults fielded between 2015 and 2018. To recap, I examine three hypotheses:

Hypothesis 1: Individuals who identify with the political right (versus left) should evaluate Pope Francis more negatively (versus positively).

Hypothesis 2a: Catholic religious affiliation should weaken the relationship between ideology and evaluations of Pope Francis, such that right-wing identification should be more weakly associated with negative views of Francis among Catholics.

\footnotetext{
${ }^{1}$ The present study focuses on Americans' attitudes toward Pope Francis, but it is worth noting that data collected in multiple Latin American nations in 2017 showed a different pattern than the U.S. one-namely, a very slight tendency for those who identified with the right to evaluate Francis more positively (Bohigues and Rivas 2020).
} 
Hypothesis 2b: Catholic religious affiliation should strengthen the relationship between religiosity and evaluations of Pope Francis, such that religiosity should be more strongly associated with positive views of Francis among Catholics.

Hypothesis 3: The relationship between identification with the political right (versus left) and negative (versus positive) evaluations of Pope Francis should be stronger among individuals who are higher in political engagement.

In addition to testing these hypotheses, I follow up with an exploratory analysis how ideology and religiosity compare to adherence to specific elements of Catholic religious life (e.g., specific Catholic beliefs and practices) as predictors of evaluations of the pope.

\section{Methods}

\section{Data Sources}

I rely on data from three national surveys. Two of these were commissioned by the Pew Research Center: The 2015 Survey of U.S. Catholics and Family Life ('2015 Pew' hereafter; the survey included both Catholics and non-Catholics), conducted between 5 May and 7 June 2015 by Princeton Survey Research Associates International; and the January 2018 Political Survey ('2018 Pew' hereafter), conducted between 10 and 15 January 2018 by Abt Associates. The 2015 Pew surveyed $N=5,122$, whereas the 2018 Pew surveyed $N=1,503$. Both full samples consisted of American adults age 18 or older, drawn from random-digit dial landline and cellphone samples provided by Survey Sampling International. The third survey was the 2016 American National Election Study time-series survey ('2016 ANES' hereafter), a dual-mode survey using a face-to-face and an internet sample conducted by Westat on behalf of the University of Michigan and Stanford University. The 2016 ANES consisted of a pre-election interview in the weeks before the 8 November 2016 election and a post-election interview conducted in the week after the election. The face-to-face component was a stratified, multi-stage cluster sample of addresses in the 48 contiguous states and DC, whereas the 
internet component was a simple random sample of addresses in the 50 states and DC. A total of $N=4,271$ completed the pre-election interview; $N=3,649$ of the pre-election respondents also completed the post-election interview. All three surveys were administered in both English and Spanish as needed.

\section{Measures}

Below, I describe the key measures from each of the three datasets. Unless otherwise indicated, all variables are recoded to run from 0-1; the descriptive statistics provided are for these 01 codings. Detailed information about the measures can be found in the Supporting information.

Francis approval. In the 2015 and 2018 Pew surveys, this was measured using a single item asking respondents' overall opinion of Pope Francis (among other figures). The item used a fourpoint response scale: very favorable, mostly favorable, mostly unfavorable, or very unfavorable. Scores were recoded so that higher scores indicated greater approval $(M=0.56, S D=0.20$, in 2015; $M=0.51, S D=0.22$, in 2018). In the 2016 ANES, approval was measured using respondents' standard 0-100 feeling thermometer rating of Pope Francis (with 100 indicating the "warmest" rating). Respoonses were again coded so that higher scores indicated greater approval $(M=0.70$, $S D=0.25)$.

Ideology. In the 2015 and 2018 Pew surveys, ideology was measured using a five-point scale: "very conservative," “conservative," “moderate," "liberal," “very liberal." Responses were reversed so that higher scores indicated greater conservatism $(M=0.53, S D=0.27$, in $2015 ; M=0.52, S D=0.27$, in 2018). In the 2016 ANES, ideology was measured using a standard seven-point scale ranging from “extremely liberal” to "extremely conservative." Higher scores indicated greater conservatism $(M=0.53, S D=0.27)$.

Religiosity. In the 2015 Pew, religiosity was operationalized using a three-item scale. These items asked how important religion was in the respondent's life (on a four-point scale from "very 
important" to "not at all important"), how often the respondent prayed (a seven-point scale from "several times a day" to "never"), and how often the respondent attended religious services (a sixpoint scale ranging from "more than once a week" to "never"). All items were recoded so that higher scores indicated greater religiosity and then averaged form a scale $(\alpha=0.85 ; M=0.64$, $S D=0.30)$. In the 2016 ANES, religiosity was operationalized as a composite of items asking about how much guidance religion provides in day-to-day life (“some," "quite a bit," "a great deal”) and how often the respondent attended religious services (a five-point scale ranging from "every week" to "never"). The two items were recoded so that higher scores indicated greater guidance and attendance. Since they were highly correlated $(r=0.65, p<0.001)$, they were averaged form a scale ( $M=0.44, S D=0.37)$. The 2018 Pew did not include a full complement of religiosity items, but it did include the attendance item from the 2015 Pew. This item was included as a covariate in the main 2015 analyses and in other analyses included in the supporting information $(M=0.49, S D=0.32)$. Catholic affiliation. This was operationalized using a dummy variable $(1=$ Catholic, $0=$ not Catholic). The 2015 Pew included 1,016 Catholics and the 2018 Pew included 316 Catholics, whereas the 2016 ANES included 927 Catholics.

Political engagement (ANES only). A composite measure of political engagement was computed as the average of nine items in the ANES. Eight of these were dichotomously-scored $(1=$ correct, $0=$ not correct or did not know) political information items. The final item was the standard ANES item asking how often the respondent paid attention to politics and election; responses to this item were given on a five-point scale ranging from "always" to "never." Responses to the attention item were reversed. Once recoded to run from $0-1$, the nine items were averaged form an engagement scale; higher scores indicated greater engagement $(\alpha=0.76 ; M=0.60, S D=0.26)$.

Partisanship. In the 2015 and 2018 Pew surveys, a five-point partisanship scale was generated from two branching items. The final scale consisted of the following: "Democrat," 
“independent/lean Democrat," "pure independent," “independent/lean Republican,” and

"Republican" (2015: $M=0.46, S D=0.40 ; 2018: M=0.45, S D=0.41)$. In the 2016 ANES, partisanship

was operationalized using a standard seven-point scale ranging from "strong Democrat" to "strong Republican" ( $M=0.48, S D=0.36)$. Higher scores indicated a stronger identification with the Republican Party in all surveys.

Demographic covariates. Several demographic covariates were also considered. These included age (in years), income, education (five ordered categories), a dummy variable for male gender (1=yes, $0=\mathrm{no})$, and a dummy variable indicating whether the respondent is $W$ bite $(1=\mathrm{yes}, 0=\mathrm{no}){ }^{2}$

\section{Results}

\section{Do Those Who Identify with the Right Evaluate Pope Francis More Negatively?}

Hypothesis 1 predicts that individuals who identify with the political right should evaluate Pope Francis more negatively. To examine this hypothesis, evaluations of Pope Francis were regressed on ideology in each dataset using ordinary least squares. All models included age, income, a dummy variable indicating whether the respondent is White, a dummy variable indicating whether the respondent is male, and a dummy variable indicating whether the respondent is Catholic. To account for potential overlap between religiosity and political conservatism, the 2015 Pew and 2016 ANES also included the composite religiosity measure, while the 2018 Pew included that survey's attendance measure. The 2016 ANES model also included political engagement as a covariate. In each dataset, we estimate two models: Model 1, which includes ideology and the covariates only; and

${ }^{2}$ The Supporting information also report robustness checks of the key analyses presented below with several additional covariates included, i.e., dummy variables for whether the respondent was evangelical, Latino, married, living in the South, and living in an urban or a suburban area (with rural residence as the reference group for the latter two variables). The results of these analyses are substantively identical to those reported here, and few of the additional covariates reach significance. The one exception to the latter is that evangelicals evaluate Pope Francis more negatively (net of the other predictors) in the 2015 Pew and 2016 ANES. 
Model 2, which adds partisanship to better isolate the predictive role of ideology. ${ }^{3}$ Ordinary leastsquares was used to estimate all models, and survey weights were applied; variance estimates in the 2016 ANES were also corrected for the sampling design.

Table 1: Evaluation of Pope Francis as a Function of Political Ideology

\begin{tabular}{|c|c|c|c|c|c|c|}
\hline \multirow[b]{2}{*}{ Predictor } & \multicolumn{3}{|c|}{ Model 1} & \multicolumn{3}{|c|}{ Model 2} \\
\hline & $b$ & $95 \% C I$ & $p$ & $b$ & $95 \% C I$ & $p$ \\
\hline $\begin{array}{l}2015 \text { Pew: } \\
\text { Ideology } \\
\text { Partisanship } \\
N\end{array}$ & $\begin{array}{l}-0.11 \\
-- \\
3328\end{array}$ & $\begin{array}{c}{[-0.14,-0.07]} \\
--\end{array}$ & $\begin{array}{c}<0.001 \\
--\end{array}$ & $\begin{array}{l}-0.08 \\
-0.04 \\
3273\end{array}$ & $\begin{array}{l}{[-0.12,-0.04]} \\
{[-0.07,-0.02]}\end{array}$ & $\begin{array}{l}<0.001 \\
<0.001\end{array}$ \\
\hline $\begin{array}{l}\text { 2016 ANES: } \\
\text { Ideology } \\
\text { Partisanship } \\
N\end{array}$ & $\begin{array}{l}-0.21 \\
-- \\
3266\end{array}$ & $\begin{array}{c}{[-0.25,-0.16]} \\
--\end{array}$ & $\begin{array}{c}<0.001 \\
--\end{array}$ & $\begin{array}{l}-0.15 \\
-0.06 \\
3262\end{array}$ & $\begin{array}{l}{[-0.22,-0.08]} \\
{[-0.11,-0.01]}\end{array}$ & $\begin{array}{r}<0.001 \\
0.014\end{array}$ \\
\hline $\begin{array}{l}2018 \text { Pew: } \\
\text { Ideology } \\
\text { Partisanship } \\
N\end{array}$ & $\begin{array}{l}-0.15 \\
-- \\
1123\end{array}$ & $\begin{array}{c}{[-0.22,-0.08]} \\
--\end{array}$ & $\begin{array}{c}<0.001 \\
--\end{array}$ & $\begin{array}{l}-0.07 \\
-0.11 \\
1108\end{array}$ & $\begin{array}{c}{[-0.15,0.01]} \\
{[-0.16,-0.06]}\end{array}$ & $\begin{array}{r}0.086 \\
<0.001\end{array}$ \\
\hline
\end{tabular}

Note. Entries are ordinary least-squares regression coefficients. Survey weights are applied in all datasets; variance estimates in the 2016 ANES analyses also correct for survey design. All models control for age, income, a dummy variable indicating whether the respondent is White, a dummy variable indicating whether the respondent is male, and a dummy variable indicating whether the respondent is Catholic. The 2015 Pew and 2016 ANES datasets also include a composite measure of

${ }^{3}$ The Francis evaluation measure in the 2015 and 2018 Pew surveys is limited in two respects: (1) it uses a four-category ordinal response scale, as opposed to a continuous one; (2) it includes a large number of missing observations due to respondents who were unable to identify or offer an evaluation of Pope Francis. For simplicity of interpretation, I present OLS estimates in the text. However, the models were estimated using alternative methods to ensure robustness of the OLS results. To address the first problem, the 2015 and 2018 Pew models from Table 1 were re-estimated using ordinal logit. To address the second problem, the 2015 and 2018 models were re-estimated using maximum-likelihood Heckman selection models. Both of these alternate procedures produced results comparable to those in Table 1. Additional details can be found in the Supporting information. 
religiosity, while the 2018 Pew includes a measure of religious attendance. The 2016 ANES also includes a measure of political engagement.

The results of these analyses are summarized in Table 1. Consistent with Hypothesis 1, Model 1 reveals a significant negative relationship between ideology and evaluations of Pope Francis, indicating that respondents who identified with the political right evaluated Francis more negatively (all $p$ s $<0.001$ ). Given the $0-1$ codings of the variables, these estimates indicating that moving from the most right-wing ideological identification to the most left-wing one is associated with an 11\% less positive evaluation of Pope Francis in the 2015 Pew survey, a 21\% less positive evaluation in the 2016 ANES, and a 15\% less positive evaluation of in the 2018 Pew survey.

In Model 2, which adds partisanship as an additional covariate, the estimates for ideology are in the same direction but weaker in magnitude. The 2015 Pew and 2016 ANES ideology estimates remain significantly different from zero, though the estimate in the 2018 Pew survey is halved and reduced to marginal significance $(p=0.086)$. Moreover, greater Republican identification is associated with more negative assessments of Francis, suggesting a relationship between partisanship and Francis attitudes that is congruent with the one observed for ideology ( $p$ s $<0.001$ in 2015 and 2018; $p=0.014$ in 2016). However, in all surveys besides the 2018 Pew, partisanship was more weakly related than ideology to evaluations of Pope Francis. ${ }^{4}$ On the whole, then, the data are generally consistent with Hypothesis 1.

\footnotetext{
${ }^{4}$ Between the 2015 and 2018 Pew surveys, papal statements that were more politically controversial on the right received increasing attention (e.g., Laudato Si' and the apostolic exhortation Amoris Laetitia). Consistent with this, mean approval for Pope Francis dropped more among conservatives (i.e., $M=0.53, S D=0.22$ in the 2015 Pew, versus $M=0.44, S D=0.24$ in the 2018 Pew) than among non-conservatives (i.e, the pooled samples of liberals and moderates; $M=0.57, S D=0.19$ in 2015 , versus $M=0.54, S D=0.21$ in 2018). Given the strong link between ideology and partisanship in the United States, the stronger link between GOP partisanship and negative evaluations of Francis in 2018 versus the earlier years is also consistent with growth in polarization in attitudes toward the pope after 2015.
} 


\section{Ideology, Religiosity, and Francis Evaluations Across Denominational Lines}

Hypothesis 2a predicts that Catholic religious affiliation should weaken the relationship between ideology and evaluations of Pope Francis, whereas Hypothesis $2 \mathrm{~b}$ suggests that it should strengthen the relationship between religiosity and evaluations of Francis. Among Catholics, identification with the right should be more weakly related to negative Francis evaluations, and religiosity should be more strongly related to positive Francis evaluations. To examine this hypothesis, the the Ideology $\times$ Catholic and the Religiosity $\times$ Catholic interactions were examined. In addition to including the constituent lower-order terms for ideology, religiosity, and Catholic affiliation, the relevant models also included the demographics, partisanship, and in the 2016 ANES, political engagement. Since only the 2015 Pew and 2016 ANES surveys contained multiple measures of religiosity, I restrict my analysis of Hypothesis 2 to these datasets. ${ }^{5}$ In each dataset, three models were estimated: Model 1 included only the Ideology $\times$ Catholic interaction, Model 2 included only the Religiosity $\times$ Catholic interaction, and Model 3 included both interactions. Ordinary leastsquares was used to estimate all models, with survey weights applied; in the 2016 ANES, variance estimates were also corrected for the sampling design. ${ }^{6}$

The results for the 2015 Pew survey are summarized in Table 2. Consistent with Hypothesis 2, the Ideology $\times$ Catholic interaction was positive and significant in Model $1(b=0.15, p<0.001)$ and

\footnotetext{
${ }^{5}$ Parallel analyses in the 2018 Pew survey that use the religious-attendance measure in place of the religiosity measure produce similar but somewhat weaker results vis-à-vis Hypothesis 2 . These results are reported in the Supporting information.

${ }^{6}$ For simplicity of interpretation, we present OLS estimates in the text for the 2015 Pew data, despite the aforementioned limitations of the Francis evaluation measure in that dataset. As in Table 1, the models in Table 2 were again estimated using (1) ordinal logit and (2) maximum-likelihood Heckman selection models to ensure robustness of the OLS results. Both alternate estimation procedures produced results comparable to those in Table 2. Additional details are provided in the Supporting information.
} 
Model $3(b=0.12, p<0.001)$, while the Religiosity $\times$ Catholic interaction was positive and significant in Model $2(b=0.15, p<0.001)$ and Model $3(b=0.12, p<0.001)$. To break down the two interactions, conditional effects for ideology and religiosity were computed for Catholics and non-Catholics; conditional-effect estimates were based on Model 3. Each of these interactions is plotted in Figure 2. Looking first at the Ideology $\times$ Catholic interaction, the conditional effects indicated that identification with the ideological right was associated with more negative evaluations of Francis among non-Catholics $(b=-0.11, S E=0.02, p<0.001)$, whereas ideology was unrelated to Francis evaluations among Catholics $(b=0.01, S E=0.03, p>0.250)$. Given the $0-1$ codings of the variables, these estimates indicate that moving from the most left-wing position to the most right-wing position on the ideology scale was associated with a $11 \%$ decrease in the positivity of Francis evaluations among non-Catholics, whereas the same ideological shift was associated with a (nonsignificant) $1 \%$ increase in the positivity of Catholics' evaluations of Pope Francis.

Turning to the Religiosity $\times$ Catholic interaction, religiosity was unrelated to evaluations of Francis among non-Catholics $(b=0.02, S E=0.02, p>0.250)$, but associated with more positive views of Francis among Catholics $(b=0.14, S E=0.03, p<0.001)$. These conditional-effect estimates indicate that moving from minimum to maximum religiosity was associated with a (non-significant) $2 \%$ increase in the positivity of Francis evaluations among non-Catholics and $14 \%$ increase in the positivity of evaluations of Pope Francis among Catholics. 
Table 2: Evaluation of Pope Francis as a Function of Political Ideology, Religiosity, and Denomination (2015 Pew)

\begin{tabular}{|c|c|c|c|c|c|c|c|c|c|}
\hline \multirow[b]{2}{*}{ Predictor } & \multicolumn{3}{|c|}{ Model 1} & \multicolumn{3}{|c|}{ Model 2} & \multicolumn{3}{|c|}{ Model 3} \\
\hline & $b$ & $95 \% C I$ & $p$ & $b$ & $95 \% C I$ & $p$ & $b$ & $95 \% C I$ & $p$ \\
\hline Age & 0.07 & {$[0.04,0.10]$} & $<0.001$ & 0.07 & {$[0.04,0.10]$} & $<0.001$ & 0.07 & {$[0.04,0.10]$} & $<0.001$ \\
\hline Income & 0.03 & {$[0.01,0.06]$} & 0.021 & 0.04 & {$[0.01,0.06]$} & 0.014 & 0.03 & {$[0.01,0.06]$} & 0.016 \\
\hline White $(1=$ yes $)$ & 0.01 & {$[-0.01,0.03]$} & $>0.250$ & 0.01 & {$[-0.01,0.03]$} & $>0.250$ & 0.01 & {$[-0.01,0.03]$} & $>0.250$ \\
\hline Education & 0.03 & {$[-0.001,0.06]$} & 0.063 & 0.03 & {$[0.0002,0.06]$} & 0.048 & 0.03 & {$[-0.002,0.06]$} & 0.064 \\
\hline Male $(1=$ yes $)$ & -0.01 & {$[-0.03,0.01]$} & 0.185 & -0.01 & {$[-0.03,0.01]$} & 0.197 & -0.01 & {$[-0.03,0.01]$} & 0.212 \\
\hline Catholic $(1=$ yes $)$ & 0.03 & {$[-0.01,0.07]$} & 0.166 & -0.005 & {$[-0.05,0.04]$} & $>0.250$ & -0.04 & {$[-0.09,0.01]$} & 0.123 \\
\hline Religiosity & 0.03 & {$[0.004,0.06]$} & 0.028 & 0.01 & {$[-0.02,0.04]$} & $>0.250$ & 0.02 & {$[-0.01,0.05]$} & $>0.250$ \\
\hline Partisanship & -0.04 & {$[-0.07,-0.02]$} & $<0.001$ & -0.04 & {$[-0.07,-0.02]$} & $<0.001$ & -0.04 & {$[-0.07,-0.02]$} & $<0.001$ \\
\hline Ideology & -0.11 & {$[-0.16,-0.07]$} & $<0.001$ & -0.08 & {$[-0.12,-0.04]$} & $<0.001$ & -0.11 & {$[-0.15,-0.06]$} & $<0.001$ \\
\hline Ideology $\times$ Catholic & 0.15 & {$[0.08,0.21]$} & $<0.001$ & -- & -- & -- & 0.12 & {$[0.06,0.19]$} & 0.001 \\
\hline Religiosity $\times$ Catholic & -- & -- & -- & 0.15 & {$[0.09,0.22]$} & $<0.001$ & 0.12 & {$[0.05,0.18]$} & 0.001 \\
\hline Intercept & 0.52 & {$[0.49,0.56]$} & $<0.001$ & 0.52 & {$[0.49,0.55]$} & $<0.001$ & 0.53 & {$[0.50,0.56]$} & $<0.001$ \\
\hline$F(\mathrm{df})$ & \multirow{3}{*}{\multicolumn{3}{|c|}{$\begin{array}{c}32.06(10,3263), p<0.001 \\
0.101 \\
3,273\end{array}$}} & \multirow{3}{*}{\multicolumn{3}{|c|}{$\begin{array}{r}33.31(10,3263) \\
0.100 \\
3,273\end{array}$}} & \multirow{3}{*}{\multicolumn{3}{|c|}{$\begin{array}{r}32.13(11,3262), \\
0.104 \\
3,273\end{array}$}} \\
\hline $\mathrm{R}^{2}$ & & & & & & & & & \\
\hline$N$ & & & & & & & & & \\
\hline
\end{tabular}

Note. Entries are ordinary least-squares regression coefficients. Survey weights are applied. 
Evaluation of Pope Francis as a Function of Ideology and Denomination

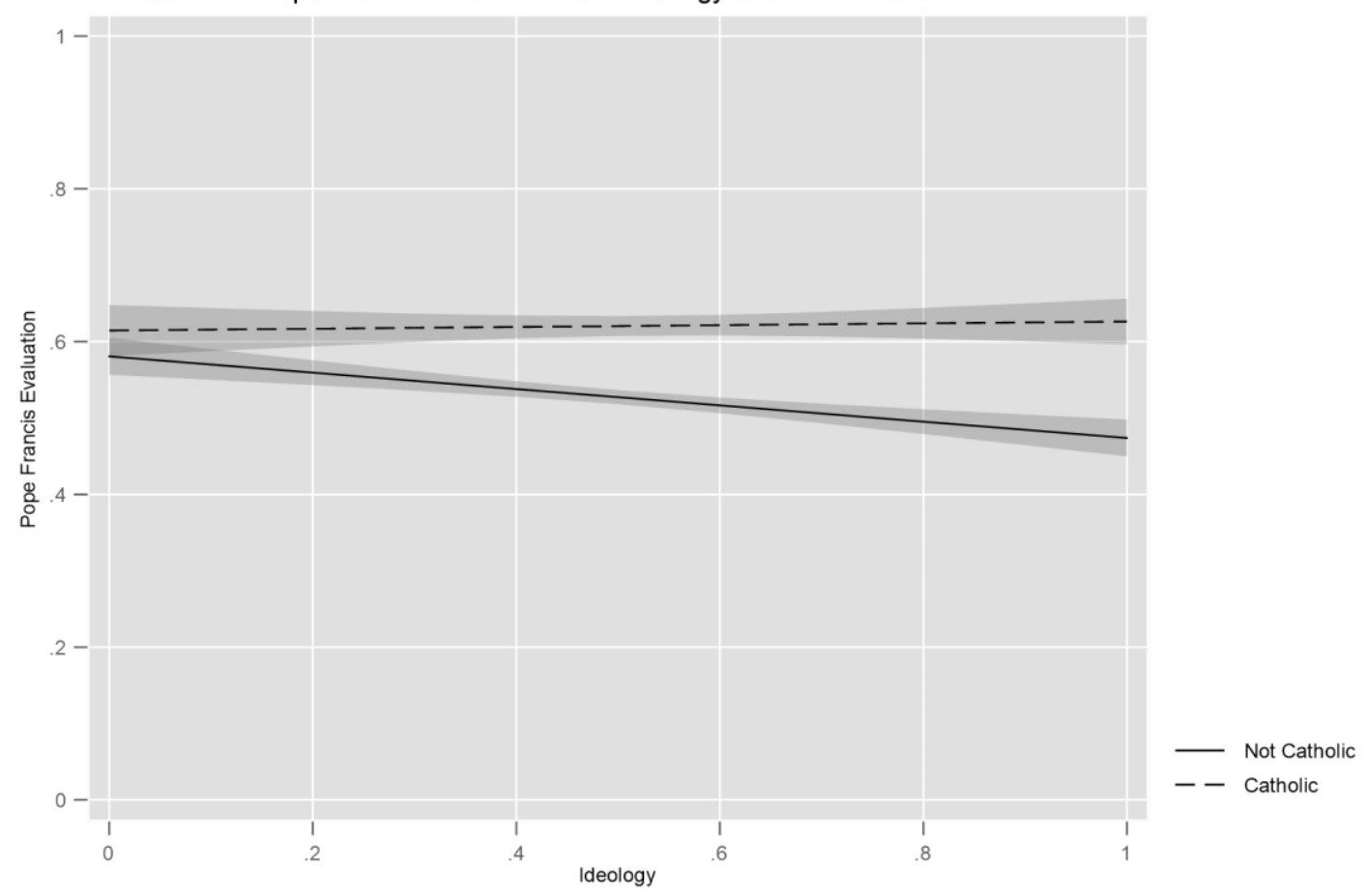

Evaluation of Pope Francis as a Function of Religiosity and Denomination

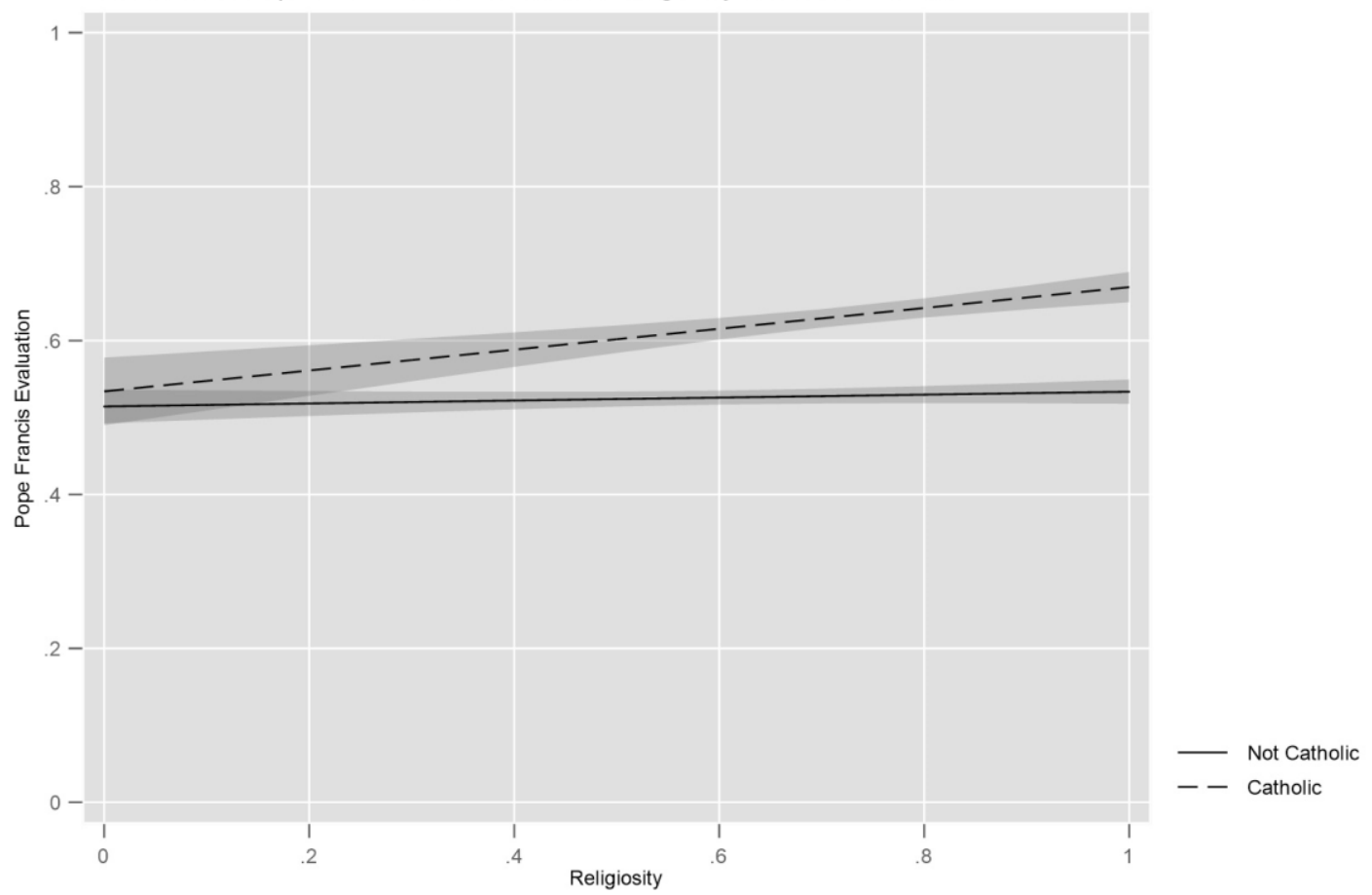

Figure 1: Evaluation of Pope Francis as a function of political ideology, religiosity, and denomination. Predicted values based on estimates from Model 3 in Table 2. (2015 Pew) 
The corresponding analyses in the 2016 ANES are shown in Table 3. Once again supporting Hypothesis 2a, the Ideology $\times$ Catholic interaction was positive and significant in Model $1(b=0.29$, $p<0.001)$ and Model $3(b=0.23, p<0.001)$. Supporting Hypothesis $2 \mathrm{~b}$, the Religiosity $\times$ Catholic interaction was positive and significant in Model $2(b=0.18, p<0.001)$ and Model $3(b=0.13$, $p<0.001)$. To make sense of each interaction, conditional effects for ideology and religiosity were again computed for Catholics and non-Catholics. As in the 2015 Pew survey, these conditionaleffect estimates were based on Model 3. The two interactions are plotted in Figure 3.

With respect to the Ideology $\times$ Catholic interaction, identification with the right was associated with more negative evaluations of Francis among non-Catholics $(b=-0.18, S E=0.03$, $p<0.001)$, whereas it was non-significantly associated with more positive views of Francis among Catholics $(b=0.04, S E=0.06, p>0.250)$. Given the variable codings, these conditional effects indicate that moving from the most left-wing identification to the most right-wing identification was associated with a $18 \%$ drop in the positivity of evaluations of the pope among non-Catholics. In contrast, the same ideological shift was associated with a (non-significant) $4 \%$ increase in the positivity of Catholics' evaluations of Francis.

Breaking down the Religiosity $\times$ Catholic interaction in a similar fashion, religiosity was unrelated to attitudes toward Pope Francis among non-Catholics $(b=0.02, S E=0.02, p>0.250)$, whereas it was associated with more positive evaluations of Pope Francis among Catholics $(b=0.15$, $S E=0.03, p<0.001)$. These conditional-effect estimates indicate that moving from the lowest to the highest level of religiosity was associated with a (non-significant) $2 \%$ increase in the positivity of Francis evaluations among non-Catholics and 14\% boost in the positivity of feelings toward the pontiff among Catholics.

Thus, analyses of both the 2015 Pew survey and the 2016 ANES provide clear support for Hypotheses $2 \mathrm{a}$ and $2 \mathrm{~b}$. 
Table 3: Evaluation of Pope Francis as a Function of Political Ideology, Religiosity, and Denomination (2016 ANES)

\begin{tabular}{|c|c|c|c|c|c|c|c|c|c|}
\hline \multirow[b]{2}{*}{ Predictor } & \multicolumn{3}{|c|}{ Model 1} & \multicolumn{3}{|c|}{ Model 2} & \multicolumn{3}{|c|}{ Model 3} \\
\hline & $b$ & $95 \% C I$ & $p$ & $b$ & $95 \% C I$ & $p$ & $b$ & $95 \% C I$ & $p$ \\
\hline Age & 0.20 & {$[0.14,0.26]$} & $<0.001$ & 0.20 & {$[0.14,0.26]$} & $<0.001$ & 0.20 & {$[0.14,0.26]$} & $<0.001$ \\
\hline Income & 0.07 & {$[0.02,0.11]$} & 0.004 & 0.07 & {$[0.02,0.11]$} & 0.003 & 0.07 & {$[0.02,0.11]$} & 0.003 \\
\hline White $(1=$ yes $)$ & 0.03 & {$[0.005,0.06]$} & 0.023 & 0.04 & {$[0.01,0.06]$} & 0.013 & 0.03 & {$[0.01,0.06]$} & 0.017 \\
\hline Education & 0.01 & {$[-0.04,0.05]$} & $>0.250$ & 0.004 & {$[-0.04,0.05]$} & $>0.250$ & 0.01 & {$[-0.04,0.05]$} & $>0.250$ \\
\hline Male (1 = yes) & -0.04 & {$[-0.06,-0.03]$} & $<0.001$ & -0.05 & {$[-0.07,-0.03]$} & $<0.001$ & -0.05 & {$[-0.06,-0.03]$} & $<0.001$ \\
\hline Catholic $(1=$ yes $)$ & 0.003 & {$[-0.05,0.06]$} & $>0.250$ & 0.07 & {$[0.03,0.12]$} & $<0.001$ & -0.02 & {$[-0.08,0.03]$} & $>0.250$ \\
\hline Religiosity & 0.04 & {$[0.01,0.07]$} & 0.017 & 0.003 & {$[-0.03,0.04]$} & $>0.250$ & 0.02 & {$[-0.02,0.05]$} & $>0.250$ \\
\hline Partisanship & -0.06 & {$[-0.11,-0.02]$} & 0.008 & -0.06 & {$[-0.11,-0.01]$} & 0.011 & -0.06 & {$[-0.11,-0.02]$} & 0.008 \\
\hline Ideology & -0.20 & {$[-0.27,-0.13]$} & $<0.001$ & -0.14 & {$[-0.21,-0.08]$} & $<0.001$ & -0.18 & {$[-0.25,-0.11]$} & $<0.001$ \\
\hline Political Engagement & 0.05 & {$[0.003,0.10]$} & 0.034 & 0.05 & {$[0.01,0.10]$} & 0.020 & 0.05 & {$[0.04,0.10]$} & 0.032 \\
\hline Ideology $\times$ Catholic & 0.29 & {$[0.20,0.38]$} & $<0.001$ & -- & -- & -- & 0.23 & {$[0.12,0.33]$} & $<0.001$ \\
\hline Religiosity $\times$ Catholic & -- & -- & -- & 0.18 & {$[0.12,0.25]$} & $<0.001$ & 0.13 & {$[0.06,0.20]$} & 0.001 \\
\hline Intercept & 0.59 & {$[0.53,0.66]$} & $<0.001$ & 0.58 & {$[0.51,0.65]$} & $<0.001$ & 0.60 & {$[0.53,0.66]$} & $<0.001$ \\
\hline$F(\mathrm{df})$ & \multicolumn{3}{|c|}{$38.64(11,123), p<0.001$} & \multicolumn{3}{|c|}{$42.91(11,123), p<0.001$} & \multicolumn{3}{|c|}{$41.44(12,122), p<0.001$} \\
\hline$R^{2}$ & \multicolumn{3}{|c|}{0.181} & \multicolumn{3}{|c|}{0.179} & \multicolumn{3}{|c|}{0.186} \\
\hline$N$ & \multicolumn{3}{|c|}{3,262} & \multicolumn{3}{|c|}{3,262} & \multicolumn{3}{|c|}{3,262} \\
\hline
\end{tabular}

Note. Entries are ordinary least-squares regression coefficients. Survey weights are applied; variance estimates also correct for survey design. 


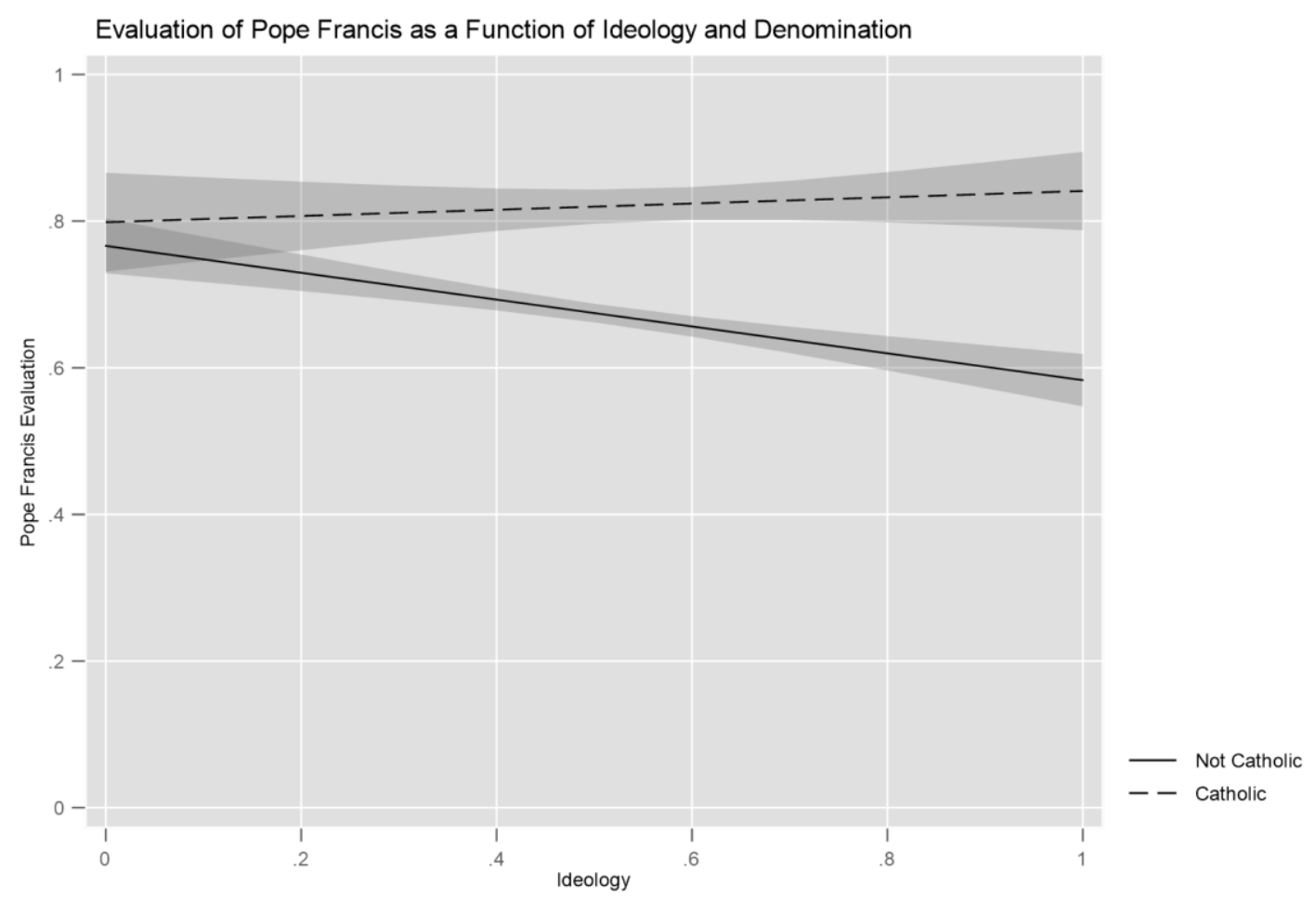

Evaluation of Pope Francis as a Function of Religiosity and Denomination

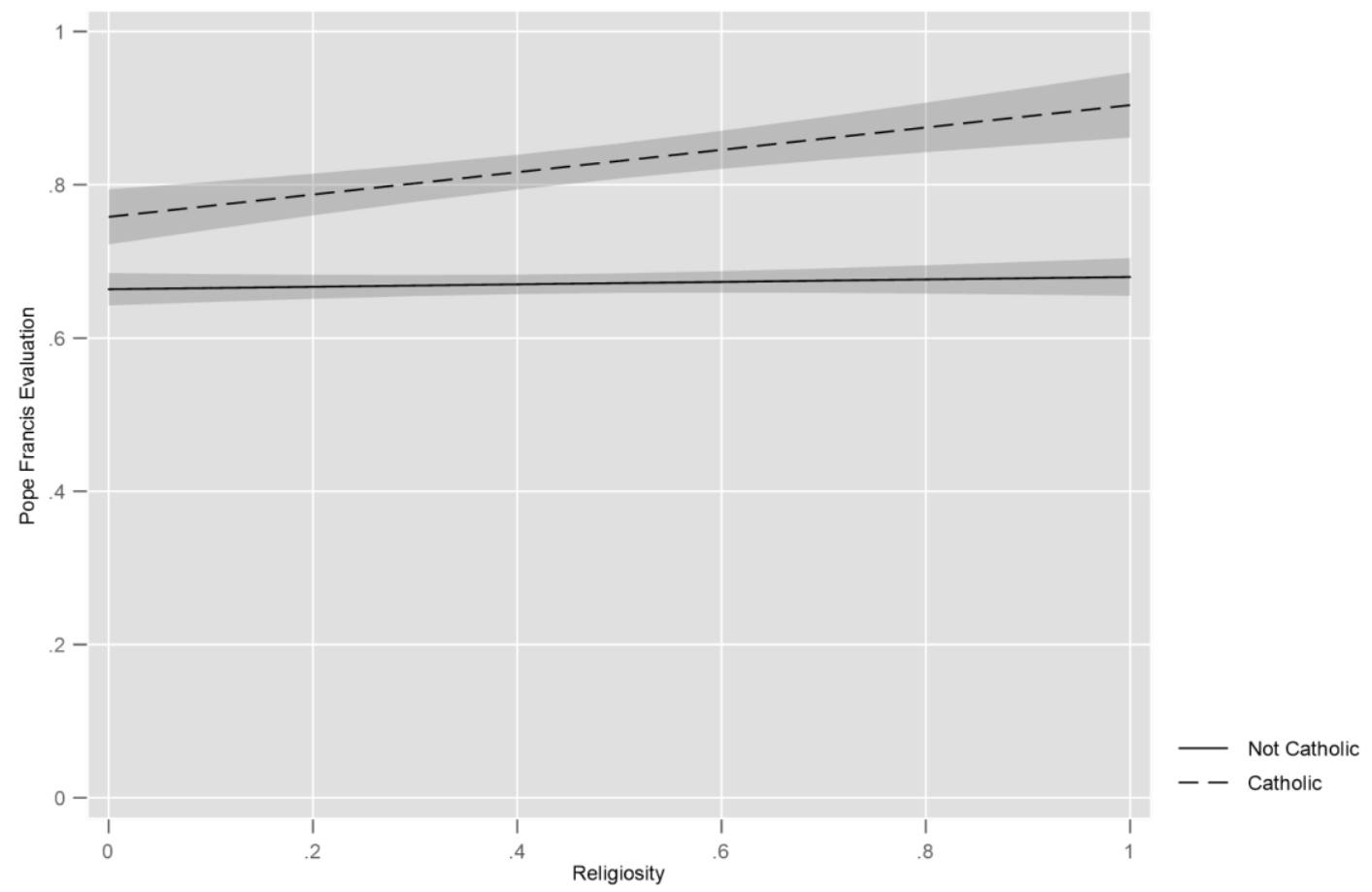

Figure 2: Evaluation of Pope Francis as a function of political ideology, religiosity, and denomination. Predicted values based on estimates from Model 3 in Table 3. (2016 ANES) 
POPE FRANCIS - 21

\section{Ideology, Political Engagement, and Evaluations of Pope Francis}

Hypothesis 3 predicts that the relationship between identification with the political right and negative evaluations of Pope Francis should be stronger among respondents higher in political engagement, given that engaged respondents are more likely to possess the sophistication needed to make ideologically-informed political judgments (e.g., Converse 1964). To test this prediction, the interaction between ideology and political engagement was examined. Since only the 2016 ANES includes an engagement measure, I rely solely on that survey to examine Hypothesis 3. In addition to the key interaction and the constituent lower-order terms for ideology and engagement, the relevant models also included the demographics, Catholic affiliation, religiosity, and partisanship. Two models were estimated. Model 1 included only the key Ideology $\times$ Political Engagement interaction. Given the significant interactions in Tables 2 and 3, Model 2 also added the Ideology $\times$ Catholic and the Religiosity $\times$ Catholic interactions. All models were estimated using ordinary least-squares; survey weights were applied, and the variance estimates were also corrected for the sampling design of the 2016 ANES.

The results are summarized in Table 4. Both Models 1 and 2 indicate a significant interaction between ideology and engagement; the estimate was identical in each model $(b=-0.39, p<0.001)$. The negative sign on the interaction suggests that the relationship between ideology and evaluations of Pope Francis becomes more negative as engagement increases, consistent with Hypothesis 3. To unpack the interaction, conditional effects for the relationship between ideology and Francis evaluations were estimated at engagement levels one standard deviation below (low engagement: 0.34) and above (high engagement: 0.86) the mean of engagement; the estimates from Model 2 were used to compute the conditional effects. This pattern of interaction is plotted in Figure 3. Among those low in engagement, ideology was essentially unrelated to evaluations of Pope Francis $(b=-0.01$, $S E=0.05, p>0.250)$. In contrast, among those high in engagement, the relationship was more 
strongly negative and statistically different from zero $(b=-0.21, S E=0.04, p<0.001)$. Given the $0-1$ codings of the variables on both sides of the equation, these conditional-effect estimates indicate that going from the most left-leaning to the most right-leaning identification on the ideology scale was associated with a $1 \%$ decrease in the positivity of evaluations of the pontiff among those low in engagement, but a much larger $21 \%$ decrease in the positivity of evaluations of Francis among those high in engagement.

Thus, Hypothesis 3 is supported.

Table 4: Evaluation of Pope Francis as a Function of Political Ideology and Political Engagement (2016 ANES)

\begin{tabular}{|c|c|c|c|c|c|c|}
\hline \multirow[b]{2}{*}{ Predictor } & \multicolumn{3}{|c|}{ Model 1} & \multicolumn{3}{|c|}{ Model 2} \\
\hline & $b$ & $95 \% C I$ & $p$ & $b$ & $95 \% C I$ & $p$ \\
\hline Age & 0.21 & {$[0.15,0.27]$} & $<0.000$ & 0.20 & {$[0.15,0.27]$} & $<0.000$ \\
\hline Income & 0.06 & {$[0.02,0.11]$} & 0.007 & 0.07 & {$[0.02,0.11]$} & 0.005 \\
\hline White $(1=$ yes $)$ & 0.03 & {$[0.002,0.06]$} & 0.036 & 0.03 & {$[0.002,0.06]$} & 0.035 \\
\hline Education & 0.0003 & {$[-0.05,0.05]$} & $>0.250$ & 0.004 & {$[-0.05,0.05]$} & $>0.250$ \\
\hline Male $(1=$ yes $)$ & -0.05 & {$[-0.07,-0.03]$} & $<0.001$ & -0.05 & {$[-0.07,-0.03]$} & $<0.001$ \\
\hline Catholic $(1=$ yes $)$ & 0.16 & {$[0.13,0.19]$} & $<0.001$ & -0.02 & {$[0.13,0.19]$} & $>0.250$ \\
\hline Religiosity & 0.04 & {$[0.001,0.07]$} & 0.041 & 0.01 & {$[0.001,0.07]$} & $>0.250$ \\
\hline Partisanship & -0.05 & {$[-0.09,0.002]$} & 0.059 & -0.05 & {$[-0.09,0.002]$} & 0.039 \\
\hline Ideology & 0.11 & {$[-0.04,0.25]$} & 0.160 & 0.08 & {$[-0.04,0.25]$} & $>0.250$ \\
\hline Political Engagement & 0.26 & {$[0.14,0.38]$} & $<0.001$ & 0.25 & {$[0.14,0.38]$} & $<0.001$ \\
\hline Ideology $\times$ Engagement & -0.39 & {$[-0.59,-0.19]$} & $<0.001$ & -0.39 & {$[-0.59,-0.19]$} & $<0.001$ \\
\hline Ideology $\times$ Catholic & -- & -- & -- & 0.22 & {$[0.11,0.32]$} & $<0.001$ \\
\hline Religiosity $\times$ Catholic & -- & -- & -- & 0.14 & {$[0.07,0.21]$} & $<0.001$ \\
\hline Intercept & 0.43 & {$[0.33,0.53]$} & $<0.001$ & 0.46 & {$[0.36,0.57]$} & $<0.001$ \\
\hline$F(\mathrm{df})$ & \multirow{2}{*}{\multicolumn{3}{|c|}{$\begin{array}{c}36.78(11,123), p<0.001 \\
0.177\end{array}$}} & \multicolumn{3}{|c|}{$37.91(13,121), p<0.001$} \\
\hline$R^{2}$ & & & & \multirow{2}{*}{\multicolumn{3}{|c|}{$\begin{array}{r}0.195 \\
3262\end{array}$}} \\
\hline$N$ & \multicolumn{3}{|c|}{3,262} & & & \\
\hline
\end{tabular}

Note. Entries are ordinary least-squares regression coefficients. Survey weights are applied; variance estimates also correct for survey design. 


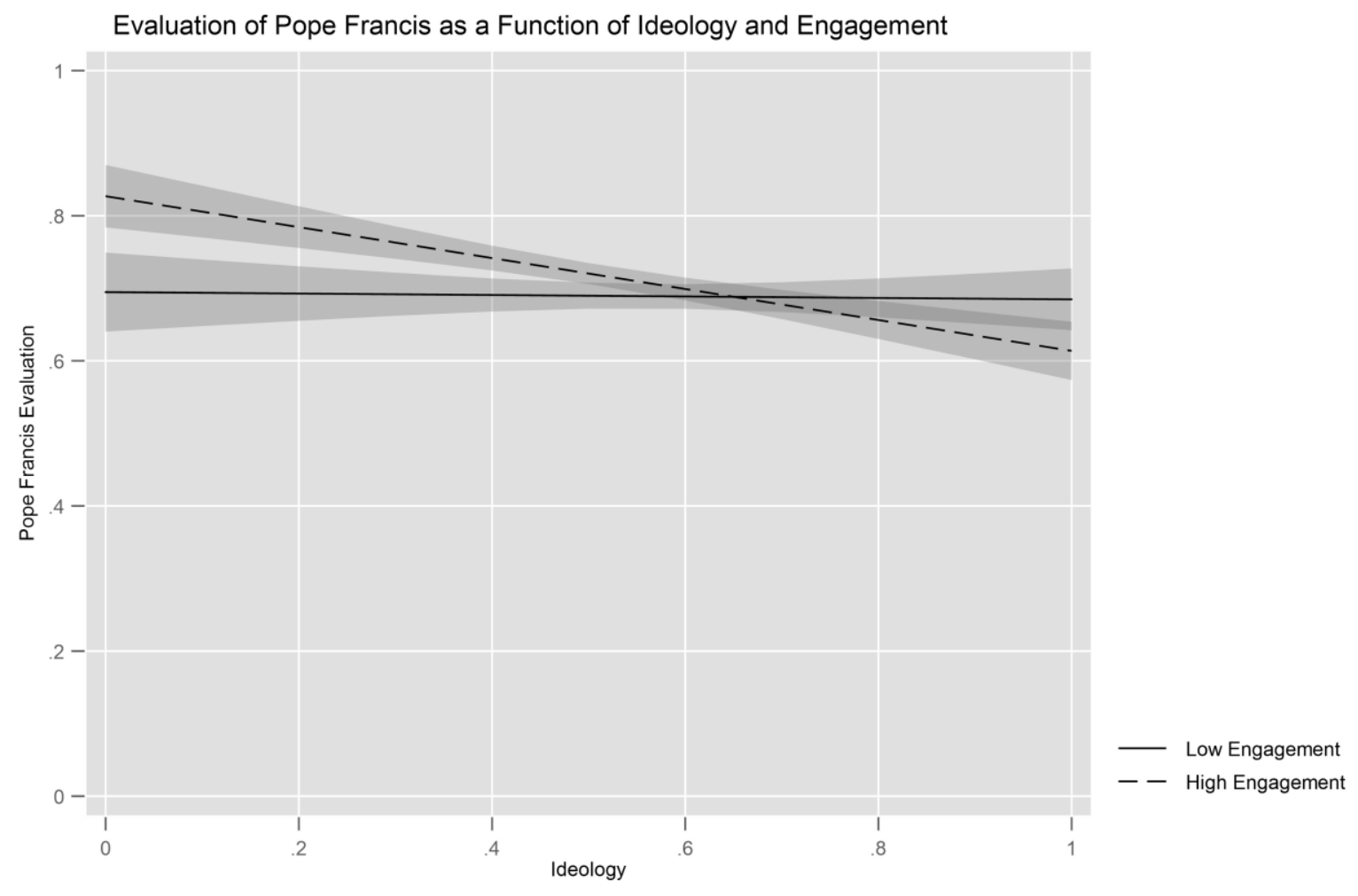

Figure 3: Evaluation of Pope Francis as a function of political ideology and political engagement. Predicted values based on estimates from Model 2 in Table 4. (2016 ANES)

\section{A Closer Look at Catholics}

As a final exploratory step, I take a closer look at factors predicting attitudes toward Pope Francis among Catholics, above and beyond ideology and religiosity. Though the results so far suggest that evaluations of Francis are related to overall religiosity (but not ideology) among Catholics, it is possible that commitment to various specific elements of Catholic life may play a role in shaping evaluations of the pontiff. To this end, I turned to the 2015 Pew study, which included the largest subsample of Catholics and numerous items about specific elements of Catholic religious life. To tap these, two sets of items were used. The first set asked about how six possible church 
reforms that would take the church in a more liberal direction (e.g., ordaining women). ${ }^{7}$ For each respondent, a count of the reforms supported were taken and then reversed and recoded to run from 0 to 1 to create a measure of doctrinal conservatism. The second set asked respondents to rate how important ten beliefs and practices were "to what being Catholic means" to them. The beliefs and practices were: receiving the sacraments, belief in Christ's resurrection, working to help the poor, being part of a parish, opposing abortion, being open to having children, addressing climate change, devotion to Mary, having a personal relationship with Christ, and celebrating feast days of national or ethnic importance. Responses to these items were coded to run from 0-1 (with higher scores indicating greater importance) and entered separately into the analysis below.

In the 2015 Pew Catholic subsample, Francis evaluations were regressed on the demographics, religiosity, ideology, the doctrinal-conservatism index, and the ten belief-and-practice variables. The model was estimated using ordinary least-squares, with survey weights applied. A forest plot of the estimates (not including demographics) are summarized in Figure $4 .{ }^{8}$ Among variables tapping specific elements of Catholic religious life, doctrinal conservatism had a slight negative relationship with evaluations of Francis $(b=-0.05, p=0.029)$, consistent with the notion that theologically-conservative Catholics feel distant from Francis (Neumayr 2017). Moreover, only one of the belief-and-practice items was significantly related to evaluations of the pope: Catholics who saw working to help the poor as more important to being Catholic evaluated Francis more positively $(b=0.05, p=0.023) .{ }^{9}$ However, these effects were dwarfed by that of general religiosity $(b=0.13$,

\footnotetext{
${ }^{7}$ The six reforms were: allowing priests to marry, ordaining women, allowing the use of birth control, recognizing gay marriage, allowing the divorced to receive communion, and allowing those living with a partner without being married to receive communion. The final doctrinal-conservatism scale was reliable $(\alpha=0.77 ; M=0.38, S D=0.33)$.

${ }^{8} \mathrm{~A}$ full table of estimates is provided in Table A13 in the supporting information.

${ }^{9}$ Somewhat surprisingly, evaluations of Francis were unrelated to how much importance Catholic respondents placed on addressing climate change $(b=-0.01, p>0.250)$, despite the pontiff's strong emphasis on the issue.
} 
$p<0.002)$. Confirming patterns reported above, ideology was unrelated to evaluations of Francis among Catholics. Thus, Catholics' evaluations of the pope appear to be more related to general religious involvement than to either ideology or specific Catholic commitments, reinforcing the above finding that overall religiosity is particularly central to Catholics' attitudes toward Francis.

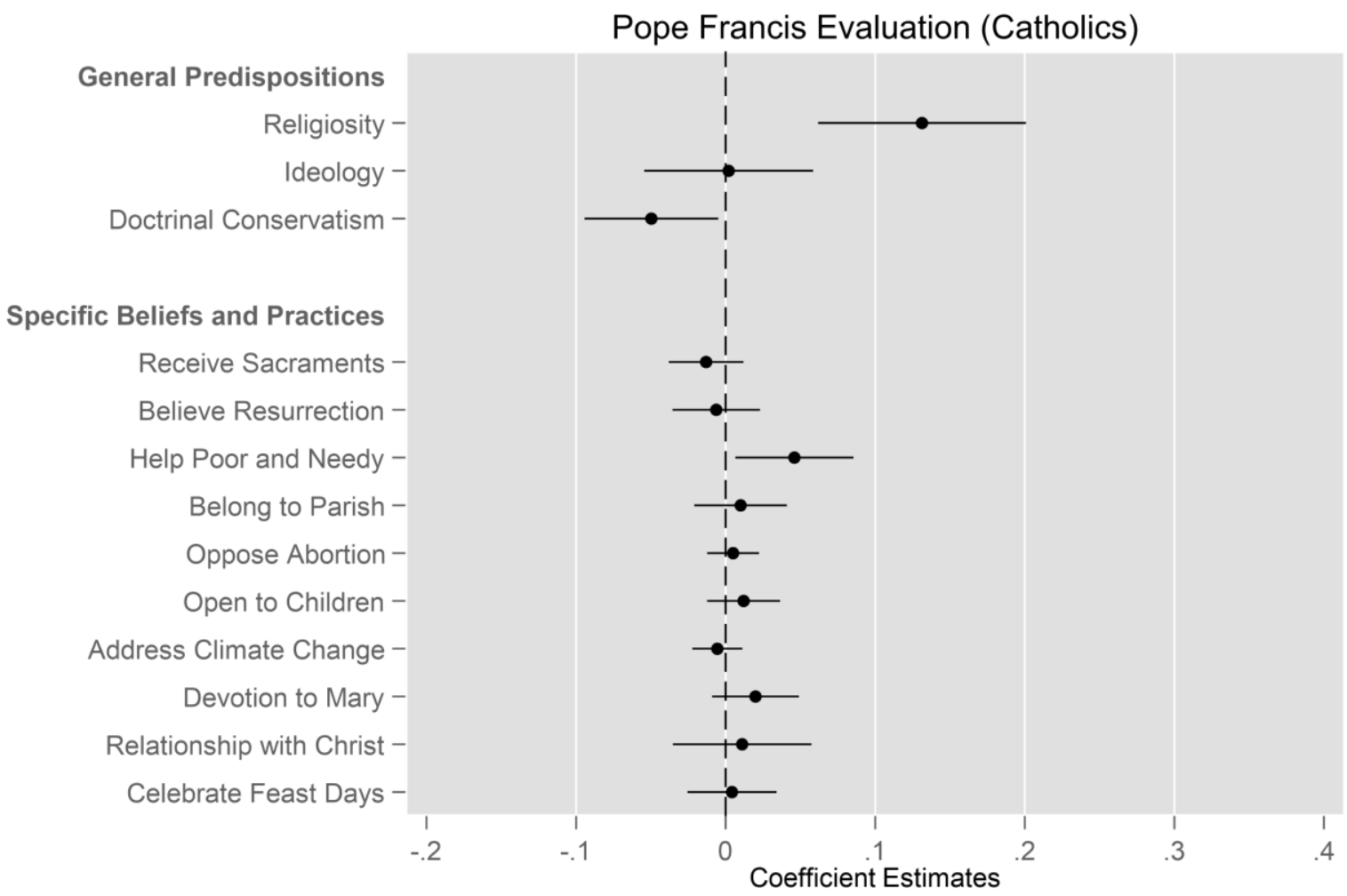

Figure 4: Predictors of evaluations of Pope Francis among Catholics. Point estimates are ordinary least-squares regression coefficients, with $95 \%$ confidence intervals. Survey weights are applied. Estimates from Table A13 in the supporting information. (2015 Pew)

\section{Discussion}

Pope Francis's high-profile statements on climate change, economic justice, and other issues has generated fervent political discussion in recent years. This has especially been the case in the United States, where responses from competing political elites have led to the coding of Francis as a

"left-wing" figure in some quarters. Despite the political reverberation of the pontiffs statements on 
social issues, little research has examined the nature of mass opinion about Francis in the United States. The present study has attempted to fill this gap by examining several hypotheses about the links between ideology, religion, and evaluations of Pope Francis in three large samples of American adults. Several core findings emerge, all of which were broadly consistent with predictions. To begin with, individuals who identified with the political right expressed more negative opinions about Francis, even after adjusting for partisanship and demographic variables. However, qualifying this, Catholic religious affiliation weakened the link between conservatism and negative evaluations of the pope, while it strengthened the tendency for respondents who expressed greater religiosity to evaluate Francis positively. Consistent with the idea that political sophistication facilitates reliance on ideology as a basis for judging social and political stimuli, the relationship between identification with the ideological right and negative evaluations of Pope Francis was also stronger among the politically engaged. Finally, an exploratory analysis among Catholics found that evaluations of the pope were more closely linked to overall religiosity, as opposed to adherence to specific elements of Catholic religious life.

Thus, the findings reported here suggest that the ideological division in reactions to Pope Francis that has been observed among political leaders and pundits is also present at the level of mass opinion. Broadly speaking, this result is consistent with the idea that disagreements among elites of from different ideological or partisan camps diffuse to those with similar views in the mass public (e.g., Converse 1964; Zaller 1992; see also Abramowitz 2010). Along these lines, it is noteworthy that the tendency for self-identified conservatives to evaluate Pope Francis more negatively was stronger among those high in political engagement, who are more likely to be aware of elite disagreement about social and political matters and adopt the elite positions that best match their own predispositions (see Federico and Malka 2018). Moreover, the existence of a mass ideological divide in opinions about Pope Francis is consistent with the idea that ideological and 
partisan polarization can extend to targets that are not strictly political in nature when symbolic connections between the target and an ideological identity—or the bases of that ideological identity_are present (Carney, Jost, Gosling, and Potter 2008; see also Jost et al. 2009). Though future research will be needed on this question, it is likely that ideological differences in evaluations of Pope Francis will persist (or perhaps deepen) to the extent that opposed political elites send different signals about the ideological coding of the issues Francis speaks to-and Francis himself.

These results also speak to a literature on the increasingly-complex interface between religion and politics in the United States. It is well-known that Americans with differing religious worldviews and overall levels of religiosity have sorted into different partisan ideological camps as political elites have taken different views on traditional morality and the importance of religion in public life (e.g., Layman 2001; Malka 2013). At the same time, a growing body of work suggests that the association between religiosity and conservative politics brought about by the emergence of the religious right may have alienated liberal and moderate individuals, reducing levels of religious commitment among the latter groups (e.g., Campbell, Layman, and Green 2021; Margolis 2018; Patrikios 2008; Putnam and Campbell, 2010). Thus, it is not merely the case that religious commitments shape political ones; political commitments feed back onto religious attitudes and behavior once religion becomes a focus of political disagreement. The present results suggest a related form of political feedback in the religious realm, albeit one different from decisions to be more or less religiously-involved. Specifically, they imply that individuals with particular ideological commitments may evaluate religious leaders on the basis of those commitments if those leaders visibly take ideologically-coded positions (e.g., criticism of economic inequality) or receive criticism from political opinion leaders (e.g., right-wing media figures).

At the same time, the present results also suggest limits to the reach of ideological disagreement about Pope Francis. Specifically, social identity in the form of Catholic affiliation 
appears to override ideological motives: in contrast to their non-Catholic compatriots, Catholics of the left and right showed little disagreement in their opinions of Pope Francis. Consistent with the idea that Francis's role as the highest group authority within Catholicism and his significance as unifying symbol of the Catholic faith tamp down ideological reactions to the pontiff among Catholics (e.g., Hogg and van Knippenberg 2003), Catholic affiliation also strengthened the relationship between religiosity and positive evaluations of Francis. Moreover, overall religious commitments of this sort—as opposed to commitment to specific beliefs and practices-was most predictive of positive attitudes toward Francis among Catholics.

In sum, ideology conditions evaluations of Pope Francis in the American public, but it appears to do so in contingent ways: its effect is weakened by Catholic identity but strengthened by political engagement. A useful way of thinking about this pattern of results is that the role of ideology in this context is governed by variables that either up-regulate or down-regulate the symbolic significance of ideological identification as a basis for evaluating a particular object—in this case, Pope Francis. On one hand, as a sizable body of public-opinion research suggests, political engagement is perhaps the most important predictor of whether people form a meaningful and wellunderstood ideological identity and use it to make judgments about objects that have acquired political relevance (Converse 1964; Federico 2015; Kinder and Kalmoe 2017; see also Federico and Malka 2018; Johnston et al 2017). For this reason, it is not surprising that evaluations of Pope Francis—a figure who has elicited different responses across the ideological spectrum among opinion leaders_-are more strongly colored by ideology among politically-engaged, ideologicallyaware citizens. On the other hand, when evaluating a figure associated with a particular religious identity, holding the identity in question should make beliefs associated with that identity more salient relative to other judgmental criteria, such as ideology (Tajfel and Turner 1986). Thus, among Catholics, it makes sense that ideology is less relevant and that religiosity — in part a broad marker of 
commitment to religious social identity (Malka 2013; Ysseldyk et al. 2010)—is more relevant to evaluations of the pontiff.

Of course, the analyses reported in this study are not without their limitations. For example, in addition to being moderated by other variables (i.e., engagement and Catholic affiliation), the overall relationships between ideological identification and evaluations of Pope Francis are modest in size in the surveys examined here. Going from the most left-wing position to the most right-wing position on the ideology measures in the three surveys are associated with negative shifts in Francis evaluation that range from only $11 \%$ to $21 \%$ when ideology is considered alone; these effect sizes are somewhat smaller once party identification is considered. Thus, while the relationship between ideology and evaluations of Pope Francis is robust and moderated by other variables in the hypothesized fashion, it is also important to not over-estimate the overall magnitude of this relationship or the role of ideology relative to other determinants of opinion toward Francis. Indeed, among Catholics, general religious involvement appears to be paramount. 


\section{References}

Abramowitz, Alan I. 2010. The Disappearing Center: Engaged Citizens, Polarization, and American Democracy. New Haven, CT: Yale University Press.

Azevedo, Flavio, John T. Jost, Tobias Rothmund, T., and Joanna Sterling. 2019. "Neoliberal ideology and the justification of inequality in capitalist societies: Why social and economic dimensions of ideology are intertwined." Journal of Social Issues 75: 49-88.

Benedict XVI. 2009. Caritas en veritate. Vatican City, Italy: Encyclical Letter, Libreria Editrice Vaticana.

Bohiques, Asbel, and Jose Manuel Rivas. 2020. "Nobody Is a Prophet in their Own Land? Evaluations of Pope Francis in Latin America.” Bulletin of Latin American Research. doi: https://doi.org/10.1111/blar.13102

Brekke, Kira. 2015. “The Pope doesn't belong in any political category, and here's why." Huffington Post. https://www.huffpost.com/entry/pope-politics n 5602ad92e4b0fde8b0d08255. Accessed October 15, 2020.

Campbell, David E., Geoffrey C. Layman, and John C. Green. 2021. Secular Surge: A New Fault Line in American Politics. New York: Cambridge University Press.

Carney, Dana R., John T. Jost, Samuel D. Gosling, and Jeff Potter. 2008. “The Secret Lives of Liberals and Conservatives: Personality Profiles, Interaction Styles, and the Things They Leave Behind." Political Psychology 29 (6): 807- 40.

Converse, Philip E. 1964. "The nature of belief systems in mass publics.” In Ideology and Discontent, D. E. Apter (ed.). New York: Free Press of Glencoe.

de la Garza, Rodolfo O., and Seung-Jin Jang. 2011. "Latino Public Opinion. In The Oxford Handbook of American Public Opinion and the Media, eds. George C. Edwards III, Lawrence R. Jacobs, and Robert Y. Shapiro, 505-519. Oxford: Oxford University Press.

Federico, Christopher M. 2015. “The structure, foundations, and expression of ideology.” In New 
directions in public opinion (2nd ed.), ed. Adam Berinsky, 81-103. New York: Routledge.

Federico, Christopher M., and Pierce D. Ekstrom. 2018. "The political self: How identity aligns preferences with epistemic needs." Psychological Science 29: 901-913. doi: $10.1177 / 0956797617748679$

Federico, Christopher M., and Ariel Malka. 2018. "The Contingent, Contextual Nature of the Relationship Between Needs for Security and Certainty and Political Preferences: Evidence and Implications." Advances in Political Psychology 39(S1): 3-48

Francis. 2015. Laudato Si': On care for our common home. Vatican City, Italy: Encyclical Letter, Libreria Editrice Vaticana.

Francis. 2020. Fratelli Tutti. Vatican City, Italy: Encyclical Letter, Libreria Editrice Vaticana.

Green, Emma. 2016. “The Bizarre Love Affair of Bernie and Francis.” The Atlantic. https://www.theatlantic.com/politics/archive/2016/04/bernie-sanders-pope-francismeeting/478740/. Accessed October 15, 2020.

Hogg, Michael A. 2005. "Social Identity and Leadership." In The psychology of leadership: New perspectives and research, eds. David M. Messick \& Roderick M. Kramer, 53-80. Mahwah, NJ: Lawrence Erlbaum Associates Publishers.

Hogg, Michael A., and Daan van Knippenberg. 2003. "Social Identity and Leadership Processes in Groups.” In Advances in experimental social psychology, Vol. 35, ed. M. P. Zanna, 1-52. New York: Academic Press. https://doi.org/10.1016/S0065-2601(03)01001-3

Ivereigh, Austen. 2019. Wounded Shepherd: Pope Francis and His Struggle to Convert the Catholic Church. New York: Henry Holt and Company.

Jacques, Peter J., Riley E. Dunlap, and Mark Freeman. 2008. “The organization of denial: Conservative think tanks and environmental skepticism." Environmental Politics 17: 349-385. https://doi.org/10.1080/09644010802055576 
John Paul II. 1987. Sollicitudo rei socialis. Vatican City, Italy: Encyclical Letter, Libreria Editrice Vaticana.

Johnston, Christopher D., Howard G. Lavine, and Christopher M. Federico. 2017. Open versus closed: Personality, identity, and the politics of redistribution. Cambridge: Cambridge University Press.

Jost, John T. 2020. A theory of system justification. Cambridge, MA: Harvard University Press.

Jost, John T., Christopher M. Federico, and Jaime L. Napier. 2009. "Political Ideology: Its Structure, Functions, and Elective Affinities." Annual Review of Psychology 60: 307- 37.

Jost, John T., Christopher M. Federico, and Jamie L. Napier. 2013. "Political Ideologies and Their Social Psychological Functions.” In The Oxford Handbook of Political Ideologies, eds. Michael Freeden, Lyman Tower Sargent, and Marc Stears, 232- 50. New York: Oxford University Press.

Jost, John T., Jack Glaser, Arie W. Kruglanski, and Frank J. Sulloway. 2003. "Political Conservatism as Motivated Social Cognition.” Psychological Bulletin 129 (3): 339- 75.

Kahan, Dan M., Ellen Peters, Maggie Wittlin, Paul Slovic, Lisa L. Ouellette, Donald Braman, and Gregory Mandel. 2012. “The polarizing impact of science literacy and numeracy on perceived climate change risks." Nature Climate Change 2: 732-735. https://doi.org/10.1038/nclimate1547

Kinder, Donald R., and Nathan P. Kalmoe. 2017. Neither liberal nor conservative: Ideological innocence in the American public. Chicago, IL: University of Chicago Press

Landrum, Asheley R., Robert B. Lull, Heather Akin, Ariel Hasell, and Kathleen Hall Jamieson. 2017. "Processing the papal encyclical through perceptual filters: Pope Francis, identity-protective cognition, and climate change concern." Cognition 166: 1-12.

Landrum, Asheley R., and Rosalynn Vasquez. 2020. "Polarized U.S. publics, Pope Francis, and climate change: Reviewing the studies and data collected around the 2015 Papal Encyclical.” WIREs Climate Change. doi: https://doi.org/10.1002/wcc.674. 
POPE FRANCIS - 33

Layman, Geoffrey. 2001. The Great Divide. New York: Columbia University Press

Levendusky, Matthew. 2009. The partisan sort: How liberals became Democrats and Conservatives Became Republicans. Chicago: Chicago University Press.

Li, Nan, Joseph Hilgard, Dietram A Scheufele, Kenneth M. Winneg, and Kathleen Hall Jamieson. 2016. “Crosspressuring conservative Catholics? Effects of Pope Francis' encyclical on the U.S. public opinion on climate change." Climatic Change 139: 367-380. http:/ / dx.doi. org/10.1007/s10584-016-1821-z.

Malka, Ariel. 2013. "Religion and domestic political attitudes around the world." In Religion, Personality, and Social Behavior, ed. Vassilis Saroglou, 230-254. New York: Taylor \& Francis.

Malka, Ariel, Yphtach Lelkes, and Christopher J. Soto. 2019. “Are Cultural and Economic Conservatism Positively Correlated? A Large-Scale Cross-National Test.” British Journal of Political Science 49: 1045-1069.

Margolis, Michele F. (2018). From politics to the pews: How partisanship and the political environment shape religious identity. Chicago: University of Chicago Press

McCright, Aaron M., Chenyang Xiao, and Riley E. Dunlap. 2014. "Political polarization on support for government spending on environmental protection in the USA, 1974-2012.” Social Science Research 48: 251-260. https://doi.org/10.1016/j.ssresearch.2014.06.008

McCright, Aaron M., Sandra T. Marquart-Pyatt, Rachael L. Shwom, Steven R. Brechin, and Summer Allen. 2016. "Ideology, capitalism, and climate: Explaining public views about climate change in the United States.” Energy Research \& Social Science 21: 180-189.

Myers, Teresa A., Connie Roser-Renouf, Edward Maibach, and Anthony Leiserowitz. 2017. "Exposure to the Pope's climate change message activated convinced Americans to take certain activism actions." Global Challenges 1(4): 1600019.

Neumayr, George. 2017. The political pope: How Pope Francis is delighting the liberal left and 
abandoning conservatives. New York: Hachette Book Group.

Norenzayan, Ara. 2014. Big Gods: How Religion Transformed Cooperation and Conflict. New Jersey: Princeton University Press.

Nortey, Justin, and Claire Gecewicz. 2020. "Three-quarters of U.S. Catholics view Pope Francis favorably, though partisan differences persist." Pew Research Center Fact Tank. https://www.pewresearch.org/fact-tank/2020/04/03/three-quarters-of-u-s-catholics-viewpope-francis-favorably-though-partisan-differences-persist/. Accessed October 15, 2020.

Patrikios, Stratos. 2008. “American Republican religion? Disentangling the causal link between religion and politics in the US." Political Behavior 30: 367-389.

Paul VI. 1971. Octogesima adveniens. Vatican City, Italy: Apostolic Letter, Libreria Editrice Vaticana.

Pew Research Center. 2015. "Positive impact of Pope Francis on views of the church, especially among Democrats and liberals." October 7, 2015. https://www.pewforum.org/2015/10/ 07/following-visit-two-thirds-in-u-s-view-pope-francis-favorably/. (Accessed October 15, 2020)

Pew Research Center. 2018. “Confidence in Pope Francis down sharply in U.S.” October 2, 2018. https://www.pewforum.org/2018/10/02/confidence-in-pope-francis-down-sharply-in-u-s/. (Accessed October 15, 2020)

Philpot, Tasha. S. 2017. Conservative but Not Republican. Cambridge University Press.

Putnam, Robert D., and David E. Campbell. 2010. American Grace: How Religion Divides and Unites Us. New York: Simon and Schuster.

Robbins, Denise. 2015. “Conservative media vs. the Pope: the worst reactions to Pope Francis' climate change encyclical." Media Matters for America. https://www.mediamatters.org/loudobbs/conservative-media-vs-pope-worst-reactions-pope-francis-climate-change-encyclical Accessed October 15, 2020. 
POPE FRANCIS - 35

Rozell, Mark J. 2018. "Introduction: The 'Catholic Vote' in the USA.” In Catholics and US Politics After the 2016 Elections, eds. Marie Gayte, Blandine Chelini-Pont, and Mark J. Rozell. London: Palgrave Macmillan, 1-22

Saavedra-Cisneros, Angel. 2017. Latino Identity and Political Attitudes: Why Are Latinos Not Republican? New York, NY Palgrave MacMillan.

Schuldt, Jonathon P., Adam R. Pearson, Rainer Romero-Canyas, and Dylan Larson-Konar. 2017. "Brief exposure to Pope Francis heightens moral beliefs about climate change." Climatic Change 141(2): 167-177. https://doi.org/10.1007/s10584-016-1893-9

Schwom, Rachael L., Aaron M. McCright, Steven R. Brechin, Riley E. Dunlap, Sandra T. MarquartPyatt, and Lawrence C. Hamilton. 2015. "Public opinion on climate change.” In Climate change and society: Sociological perspectives, eds. Riley E. Dunlap and Robert J. Brulle. New York, NY: Oxford University Press, 269-299.

Shin, Faith, and Jesse L. Preston. 2019. “Green as the Gospel: The Power of Stewardship Messages to Improve Climate Change Attitudes." Psychology of Religion and Spirituality. http://dx.doi.org/10.1037/rel0000249

Smidt, Corwin E., Lyman A. Kellstedt, and James L. Guth. 2009. “The Role of Religion inAmerican Politics: Explanatory Theories and Associated Analytical and Measurement Issues.” In Oxford Handbook on Religion and American Politics, eds. Corwin Smidt, Lyman A. Kellstedt, and James L. Guth. Oxford: Oxford University Press, 3-42.

Tajfel, H., and John C. Turner. 1986. “The Social Identity Theory of Intergroup Behavior.” In Psychology of Intergroup Relations, eds. Stephen Worchel and William G. Austin, 7-24. Chicago: Nelson-Hall Publishers.

Willis Oliver. 2015. “A 'Marxist' who should 'stay home': the worst of conservative media's war on 
Pope Francis." Media Matters for America. https://www.mediamatters.org/rush-

limbaugh/marxist-who-should-stay-home-worst-conservative-medias-war-pope-francis. Accessed October 9, 2020.

Ysseldyk, Renate, Kimberly Matheson, and Hymie Anisman. 2010. "Religiosity as Identity: Toward an Understanding of Religion From a Social Identity Perspective." Personality and Social Psychology Review 14: 60-71. https://doi.org/10.1177/1088868309349693

Zaller, John. 1992. The Nature and Origins of Mass Opinion. New York: Cambridge University Press.

\section{Supporting Information}

The following supporting information is available for this article:

Section I. Measures from the 2015 Pew, 2018 Pew, and 2016 ANES

Section II. Replication of Analyses Summarized in Table 1 (2015 and 2018 Pew)

Section III. Replication of Analyses Summarized in Table 2 (2015 Pew)

Section IV. Tests of Hypothesis 2 in the 2018 Pew Survey

Section V. Primary Models with Additional Covariates

Section VI. Predictors of Evaluations of Francis Among Catholics: Full Models (2015 Pew) 
POPE FRANCIS - 37

\section{Supporting Information}

The Ideological and Religious Bases of Attitudes Toward Pope Francis in the United States

\section{Measures from the 2015 Pew, 2018 Pew, and 2016 ANES}

\section{5 and 2018 Pew Surveys}

Item names from the original Pew surveys are indicated in parentheses in italics. The 2015 Pew survey was the 2015 Pew Research Center Survey of U.S. Catholics and Family Life, which was downloaded from https://www.pewforum.org/dataset/2015-survey-of-u-s-catholics-and-familylife/. The 2018 Pew survey was the January 2018 Political Survey, which was downloaded from https://www.pewresearch.org/politics/dataset/january-2018-political-survey/. In both studies, the created weight variable used in the analyses was weight.

Francis approval. "Next, is your overall opinion of Pope Francis very favorable, mostly favorable, mostly unfavorable, or very unfavorable?" Other coded response options included "never heard of" and "can't rate." (Q.A3.a in 2015, Q.39a in 2018)

Ideology. "In general, would you describe your political views as..." The response options were "very conservative," "conservative," "moderate," "liberal" and "very liberal." (IDEO in both 2015 and 2018)

Religiosity. Three items were used in the 2015 Pew survey: (1) "Aside from weddings and funerals, how often do you attend religious services...more than once a week, once a week, once or twice a month, a few times a year, seldom, or never?" (ATTEND); (2) "How important is religion in your life - very important, somewhat important, not too important, or not at all important?" (Q.F2); (3) "People practice their religion in different ways. Outside of attending religious services, do you pray several times a day, once a day, a few times a week, once a week, a few times a month, seldom, or never?" (Q.F5). Only the attendance item was available in the 2018 Pew survey; its wording was identical to that in the 2015 Pew (ATTEND)

Catholic affiliation. This was constructed from responses to the following item: "What is your present religion, if any? Are you Protestant, Roman Catholic, Mormon, Orthodox such as Greek or Russian Orthodox, Jewish, Muslim, Buddhist, Hindu, atheist, agnostic, something else, or nothing in particular?" Respondents who indicated "Roman Catholic" were scored as 1; all others were scored 0. (RELIG)

Partisanship. This was operationalized using responses to a pair of branching items. The first item asked, "In politics TODAY, do you consider yourself a Republican, Democrat, or independent?" Responses included "Republican," "Democrat," and "Independent," and volunteered responses of "no preference" "other party" were also coded. The second item was asked of those who gave "Independent," "no preference," "other party," or don't know responses to the first item: "As of today do you lean more to the Republican Party or more to the Democratic Party?" Responses included "Republican" and "Democrat," and "other" and don't know responses were also coded. Responses were used to create a five-point partisanship scale ranging from 0 to 4 . Respondents who indicated "Democrat" on the first item were scored as 0 , while those who indicated "Republican" on the first item were scored as 4. Respondents who indicated "Independent" or "no preference on the first item were scored as 1 if they indicated "Democrat" on 
the second item, 2 if they indicated "other" or don't know to the second item, and 3 if they indicated "Republican" on the second item. The small number of respondents who gave "other party" or "don't know" on the first item were scored as having missing data on partisanship. (PARTY, PARTYLN in both 2015 and 2018).

Age. In the 2015 Pew survey, this was measured using a fourteen-category variable. These categories were as follows: 24 or younger, 25-29, 30-34, 35-39, 40-44, 45-49, 50-54, 55-59, 60-64, 6569, 70-74, 75-79, 80-84, 85 or older. In the 2018 Pew survey, this was measured using a single item: "What is your age" Responses were coded in years. (AGEREC in 2015, AGE in 2018)

Income. In 2015, this item asked: "Last year, that is in 2014, what was your total family income from all sources, before taxes? Just stop me when I get to the right category.” In 2018, the item asked: "Last year, that is in 2017, what was your total family income from all sources, before taxes? Just stop me when I get to the right category." There were nine response categories in each survey year: less than $\$ 10,000, \$ 20,000$ to under $\$ 30,000, \$ 30,000$ to under $\$ 40,000, \$ 40,000$ to under $\$ 50,000, \$ 50,000$ to under $\$ 75,000, \$ 75,000$ to under $\$ 100,000, \$ 100,000$ to under $\$ 150,000$, and $\$ 150,000$ or more. Responses were rescaled to run from 0-1 in both Pew datasets. (INCOME in both 2015 and 2018)

Education. In both Pew surveys, the education item asked: "What is the highest level of school you have completed or the highest degree you have received?" The item had eight response options: (1) less than high school; (2) high school incomplete; (3) high school graduate; (4) some college, no degree; (5) two-year associate degree from a college or university; (6) four-year college or university degree / bachelor's degree; (7) some postgraduate or professional schooling, no degree; (8) postgraduate or professional degree. Responses were recoded to form a five-category (0-4) ordinal variable in each survey. Respondents in categories 1 and 2 were scored as 0 , respondents in category 3 were scored as 1, respondents in categories 4 and 5 were scored as 2 , respondents in category 6 were scored as 3 , and respondents in categories 7 and 8 were scored as four. Scores on the 0-4 variable were rescaled to run from 0-1. (EDUC2 in 2015, EDUC2 in 2018)

Male gender. This was measured using a single interviewer-coded item with the options "male" and "female." Respondents coded as male were scored as 1; all others were scored as 0. (SEX in both 2015 and 2018)

White. A dummy variable indicating whether the respondent was White was coded from a single created variable in each survey with the following categories: "White non-Hispanic," "Black non-Hispanic," "Hispanic," "Other," and don't know. Respondents in the "White non-Hispanic" category were scored as 1 and all others were scored as 0. (RACETHN in both 2015 and 2018)

Doctrinal conservatism. This was measured using six items, introduced with the following: "Do you think the Catholic Church should or should not..." The six items were: (1) "Allow priests to get married," (2) "Allow women to become priests," (3) "Allow Catholics to use birth control," (4) "Recognize the marriages of gay and lesbian couples," (5) "Allow divorced Catholics who remarry without getting an annulment to receive Communion," and (6) "Allow Catholics who are living with a romantic partner without being married to receive Communion." Responses included yes (coded 1) or no (coded 0). Responses were averaged to form a scale. (Q.J31a-Q.J31fin 2015) 
Specific beliefs and practices. These were measured using ten items. The items were prefaced with the following: "Please tell me how important each of the following is to what being Catholic means TO YOU PERSONALLY. The ten items were:

"Receiving the sacraments"
"Belief in Jesus' actual resurrection from the dead"
"Working to help the poor and needy"
"Being part of a Catholic parish"
"Opposing abortion"
"Being open to having children"
"Working to address climate change"
"Devotion to Mary as the virgin mother of God"
"Having a personal relationship with Jesus Christ"
"Celebrating feast days or festivals that are part of your national or ethnic heritage"

The response categories were: "Essential part of what BEING CATHOLIC means TO YOU PERSONALLY" (1), "Important but NOT essential," (2) and "Not an important part of what BEING CATHOLIC means TO YOU PERSONALLY” (3). Items were reversed and recoded to run from 0-1; higher scores indicate greater rated importance. (Q.N3a-Q.N3j in 2015)

\section{Additional covariates included in robustness checks:}

Latino. A dummy variable indicating whether the respondent was Latino was coded from the same created variable in each survey that was used to generate the White dummy variable. Respondents in the "Hispanic" category were scored as 1 and all others were scored as 0. (RACETHN in both 2015 and 2018)

South. A dummy variable indicating whether the respondent lived in the South was coded from a single created variable in each survey with the following categories: "Northeast," "Midwest," "South," and "West." Respondents in the "South" category were scored as 1 and all others were scored as 0. (CREGION in both 2015 and 2018)

Married. A dummy variable indicating whether the respondent was married was generated from responses to a single item: "Are you currently married, living with a partner, divorced, separated, widowed, or have you never been married?" Respondents who indicated "currently married" category were scored as 1 and all others were scored as 0. (MARITAL in both 2015 and 2018).

Evangelical. In both surveys, this was constructed from responses to the same general religion item used to code Catholic affiliation (RELIG) and a second item asking: "Would you describe yourself as a 'born again' or evangelical Christian, or not?” Response options included yes, no, undesignated, and don't know. (BORN) Respondents who indicated that they were "Protestant" on the first religion item and answered "yes" to the evangelical/born-again item were scored as 1; all others were scored 0 .

Urbanicity dummies. Dummy variables for urban residence and suburban residence were generated from a single created variable in the 2018 Pew with three categories: urban, suburban, and rural. The urban dummy variable was scored 1 for urban respondents and 0 for all other respondents; 
the suburban dummy variable was scored 1 for suburban respondents and 0 for all other respondents. Thus, rural residents comprised the reference group for these two variables. (USR in 2018)

\section{American National Election Study}

The 2016 ANES was the 2016 American National Election Study Time-Series survey, which was downloaded from: https://electionstudies.org/data-center/2016-time-series-study/. ANES variable names are indicated in parentheses in italics. The created weight variable used in the 2016 anes was V160102. The survey-design variables were V160201 for stratum and V160202 for cluster.

Francis approval. Evaluations of Pope Francis in the 2016 ANES were assessed using the standard feeling-thermometer item: "How would you rate POPE FRANCIS?" Respondents provided their rating on a 101-point scale ranging from 0 (coldest/most negative) to 100 (warmest/most positive), with 50 as a neutral midpoint. (V162094)

Ideology. This was measured using a single seven-point self-placement item: "Where would you place yourself on this scale, or haven't you thought much about this?" The response options were "extremely liberal" (1), "liberal" (2), "slightly liberal" (3), "moderate, middle of the road" (4), "slightly conservative" (5), "conservative" (6), and "extremely conservative." (V161126)

Religiosity. Two items were used: (1) "Would you say your religion provides some guidance in your day-to-day living, quite a bit of guidance, or a great deal of guidance" (V161242); and (2) "Do you go to religious services every week, almost every week, once or twice a month, a few times a year, or never?" (V161245). For the first item, the three listed responses were scored as 1, 2, and 3 respectively; individuals who indicated in a previous question (V161241) that religion was not an important of their life were scored as 0 . For the second item, responses were reversed. Both coded items were then rescaled to run from 0-1 before being averaged to form a single scale.

Catholic affiliation. This was constructed from responses to three items. The first item asked, "Lots of things come up that keep people from attending religious services even if they want to. Thinking about your life these days, do you ever attend religious services, apart from occasional weddings, baptisms or funerals?" (yes/no; V161244) Individuals who replied "yes" to the first item were asked, "Do you mostly attend a place of worship that is Protestant, Roman Catholic, Jewish, or something else?" (V161247a). Individuals who replied "no" to the first item were asked, "Do you consider yourself Protestant, Roman Catholic, Jewish, or something else?” (V161247b). Individuals who (1) replied "yes" to V161244 and "Catholic" to V161247a or (2) replied "no" to V161244 and "Catholic" to V161247b were scored as Catholic (1); other were scored as non-Catholic (0).

Political engagement. This variable was based on responses to eight political-information items and one political-interest item. Three information items asked about government procedure: (1) "For how many years is a United States Senator elected that is, how many ears are there in one full term of office for a U.S. Senator?” (2) "Do you happen to know which party currently has the most members in the U.S. House of Representatives in Washington?" (3) "Do you happen to know which party currently has the most members in the U.S. Senate?” (V161513, V161515, V161516). Five information items asked respondents to identify the office held by various political figures: (4) "Joe Biden What job or political office does he now hold?" (5) "Paul Ryan. What job or political office does he now hold?" (6) "Angela Merkel. What job or political office does she now hold?" (7) "Vladimir Putin. What job or political office does he now hold?" (8) "John Roberts What job or 
political office does he now hold?" (V162072, V162073a, V162074a, V162075a, V162076a). All eight information items were scored 1 if the respondent correctly answered the item and 0 if they answered incorrectly or did not know. The political-interest item was: "How often do you pay attention to what's going on in government and politics? Always, most of the time, about half the time, some of the time, or never?" (V161003). Responses to the interest item were reversed and rescaled to run from 0-1. Responses to all nine items (all scaled to a 0-1 interval) were averaged to form a single scale.

Partisanship. This was operationalized using responses to a single created ANES variable with the following categories: (1) "strong Democrat," (2) "not very strong Democrat," (3) "IndependentDemocrat," (4) "Independent," (5) "Independent-Republican," (6) "not very strong Republican," and (7) "strong Republican." This variable was created based on a standard series of branching items. (V161158x; created from V161155, V161155a, V161156, and V161157) $(V 161267)$

Age. This was based on a single created ANES variable recording the respondent's age.

Income. This was based on a single created ANES variable recording the respondent's selfreported income. There were 28 response categories. (V161361x)

Education. In the ANES, the education item asked: "What is the highest level of school you have completed or the highest degree you have received?" The item had sixteen response options: (1) less than first grade; (2) grades 1-4; (3) grades 5 or 6; (4) grades 7 or 8; (5) grade 9; (6) grade 10; (7) grade 11; (8) grade 12, no diploma; (9) high-school graduate or GED; (10) some college, no degree; (11) associate degree, vocational; (12) associate degree, academic; (13) four-year college or university degree / bachelor's degree; (14) master's degree, (15) professional degree, (16) doctoral degree. Responses were recoded to form a five-category (0-4) ordinal variable. Respondents in categories 1-8 were scored as 0 , respondents in category 9 were scored as 1 , respondents in categories 10-12 were scored as 2, respondents in category 13 were scored as 3 , and respondents in categories 14-16 were scored as 4 . Scores on the 0-4 variable were rescaled to run from 0-1. $(V 161270)$

Male gender. This was measured using a single item: "What is your gender?" Responses included "male," "female," and "other." Those who responded "male" were scored as 1; all others were scored as $0 .($ V161342)

White. A dummy variable indicating whether the respondent was White was scored from responses to a single summary item for respondent race. The six coded categories in the ANES variable were White, non-Hispanic; Black, non-Hispanic; Asian, native Hawaiian or other Pacific Islander, non-Hispanic; Native American or Alaska Native, non-Hispanic; Hispanic, and other nonHispanic including multiple races. Respondents who were coded into the "White, non-Hispanic" category were scored as 1; all others were scored as 0. (V161310x)

\section{Additional covariates included in robustness checks:}

Latino. A dummy variable indicating whether the respondent was Latino was scored from responses to the same summary item for respondent race used to create the White dumm variable. 
Respondents who were coded into the "Hispanic" category were scored as 1; all others were scored as $0 .(V 161310 x)$

South. A dummy variable indicating whether the respondent lived in the South was coded from a single created variable with the following categories: "Northeast," "Midwest," "South," and "West." Respondents in the "South" category were scored as 1 and all others were scored as 0. $(V 163003)$

Married. A dummy variable indicating whether the respondent was married was generated from responses to a single item: "Are you now married, widowed, divorced, separated or never married?" Respondents who in either of the now-married categories (spouse present, spouse absent) were scored as 1 and all others were scored as 0. (V161268).

Evangelical. This was constructed from responses to a single yes/no item: "Would you call yourself a born-again Christian, that is, have you personally had a conversion experience related to Jesus Christ?" Respondents who answered "yes" to the item were scored as 1; all others (including those who were not asked the question because they did not identify themselves as Christian in other items) were scored $0 .(v 161263)$ 


\section{Replication of Analyses Summarized in Table 1 (2015 and 2018 Pew)}

As noted in the text, the measure of respondents' evaluations of Pope Francis in the 2015 and 2018 Pew surveys is limited in two respects: (1) it uses a four-category ordinal response scale, as opposed to a continuous one; (2) it includes a large number of missing observations due to respondents who were unable to identify or offer a rating of Francis. For simplicity of interpretation, I report OLS estimates in the text.

However, the models examining Hypothesis 1 were estimated using alternative methods to ensure robustness of the OLS results. To address the first problem, the 2015 and 2018 Pew models from Table 1 were re-estimated using ordinal logit; these results are summarized in Table A1. To address the second problem, the 2015 and 2018 models were re-estimated using maximumlikelihood Heckman selection models; these results are summarized in Table A2. In all Heckman models, the outcome equation has the same specification as the corresponding OLS model in Table 1 ; in each model, the selection equation contained a single predictor-Catholic affiliation-which was positively and significantly associated with the case being selected in all instances $(\not s<0.001)$. As the results shown below suggest, both the ordinal-logit and Heckman models produced results comparable to those in Table 1 and largely consistent with Hypothesis 1.

Table A1: Evaluation of Pope Francis as a Function of Political Ideology, 2015 and 2018 Pew (Ordinal Logit)

\begin{tabular}{|c|c|c|c|c|c|c|}
\hline \multirow[b]{2}{*}{ Predictor } & \multicolumn{3}{|c|}{ Model 1} & \multicolumn{3}{|c|}{ Model 2} \\
\hline & $b$ & $95 \% C I$ & $p$ & $b$ & $95 \% C I$ & $p$ \\
\hline \multicolumn{7}{|l|}{ Pew 2015: } \\
\hline Ideology & -1.13 & {$[-1.47,-0.78]$} & $<0.001$ & -0.82 & {$[-1.21,-0.43]$} & $<0.001$ \\
\hline Partisanship & -- & -- & -- & -0.49 & {$[-0.72,-0.25]$} & $<0.001$ \\
\hline$N$ & 3328 & & & 3273 & & \\
\hline \multicolumn{7}{|l|}{ Pew 2018: } \\
\hline Ideology & -1.37 & {$[-2.03,-0.71]$} & $<0.001$ & -0.65 & {$[-1.43,0.12]$} & 0.099 \\
\hline Partisanship & -- & -- & -- & -0.98 & {$[-1.42,-0.55]$} & $<0.001$ \\
\hline$N$ & 1123 & & & 1108 & & \\
\hline
\end{tabular}

Note. Entries are ordinal logit coefficients. Survey weights are applied in all datasets. 
Table A2: Evaluation of Pope Francis as a Function of Political Ideology, 2015 and 2018 Pew (Heckman Selection Model)

\begin{tabular}{|c|c|c|c|c|c|c|}
\hline \multirow[b]{2}{*}{ Predictor } & \multicolumn{3}{|c|}{ Model 1} & \multicolumn{3}{|c|}{ Model 2} \\
\hline & $b$ & $95 \% C I$ & $p$ & $b$ & $95 \% C I$ & $p$ \\
\hline \multicolumn{7}{|l|}{ Pew 2015: } \\
\hline Ideology & -0.11 & {$[-0.14,-0.07]$} & $<0.001$ & -0.08 & {$[-0.12,-0.04]$} & $<0.001$ \\
\hline Partisanship & -- & -- & -- & -0.04 & {$[-0.07,-0.02]$} & $<0.001$ \\
\hline$N$ & 4589 & & & 4534 & & \\
\hline$\rho(\mathrm{SE})$ & \multicolumn{2}{|c|}{$-0.000001(0.000002)$} & & \multicolumn{2}{|c|}{$-0.000004(0.000002)$} & \\
\hline \multicolumn{7}{|l|}{ Pew 2018: } \\
\hline Ideology & -0.15 & {$[-0.22,-0.08]$} & $<0.001$ & -0.07 & {$[-0.15,0.01]$} & 0.086 \\
\hline Partisanship & -- & -- & -- & -0.11 & {$[-0.16,-0.06]$} & $<0.001$ \\
\hline$N$ & \multicolumn{3}{|l|}{1378} & \multicolumn{3}{|l|}{1363} \\
\hline$\rho(\mathrm{SE})$ & \multicolumn{3}{|c|}{$-0.000004(0.000005)$} & \multicolumn{3}{|c|}{$0.0000001(0.00002)$} \\
\hline
\end{tabular}

Note. Entries are coefficients from the regression equations of maximum-likelihood Heckman selection models. In all models, the selection equation contains a single predictor-Catholic affiliation - which was positively and significantly associated with the case being selected in all instances $(p \mathrm{~s}<0.001)$. Survey weights are applied in all datasets. 
POPE FRANCIS - 45

\section{Replication of Analyses Summarized in Table 2 (2015 Pew)}

Given the problems with the Pew measure of evaluations of Pope Francis, the tests of Hypothesis 2 reported in Table 2 for the 2015 Pew survey were also re-estimated using alternative methods to ensure robustness of the OLS results.

To deal with the ordinal nature of the Pew Francis evaluation's measurement scale, the models reported in Table 2 were re-estimated using ordinal logit. These results are summarized in Table A3. The ordinal-logit models produced results that were similar those in Table 2. The Ideology $\times$ Catholic interaction was positive and significant in Model $1(b=1.47, p<0.001)$ and Model 3 ( $b=1.10, p=0.006)$, while the Religiosity $\times$ Catholic interaction was positive and significant in Model $2(b=1.95, p<0.001)$ and Model $3(b=1.59, p<0.001)$. Since tests on interaction terms alone are not sufficient to establish moderation in nonlinear models due to the inherent variability of marginal effects in such models even in the absence of interactions, discrete probability changes for ideology and religiosity were computed for non-Catholics and Catholics based on average marginal effects (Ai and Norton 2003; Karaca-Mandic, Norton, and Dowd 2012). ${ }^{10}$ The estimates from Model 3 were used for these analyses. To probe the Ideology $\times$ Catholic interaction, discrete changes in the probability of giving the most positive evaluation of Francis (i.e., the top category on the ordinal response scale) associated with going from the most left-wing to the most right-wing position on the ideology scale were computed for non-Catholics and Catholics. This shift in ideology was associated with a significant decrease in the probability of giving Francis the most positive evaluative response among non-Catholics $(\Delta p=-0.22, S E=0.05, p<0.001)$, but was unrelated to shifts in the probability of giving the most positive evaluation among Catholics $(\Delta p=0.02, S E=0.08$, $p>0.250)$. To unpack the Religiosity $\times$ Catholic interaction, similar discrete probability changes were computed for a shift from minimum to maximum religiosity. The analyses indicated that a shift from the lowest to the highest religiosity level was only marginally related to giving the most positive evaluative response to Francis among non-Catholics $(\Delta p=0.06, S E=0.03, p=0.070)$, whereas the same shift in religiosity was associated a considerable increase in the probability of giving the most positive evaluative response to Francis among Catholics $(\Delta p=0.43, S E=0.08, p<0.001)$.

To address the problem of possible sample selection in the Francis Pew evaluation scale, the models in Table 2 were also re-estimated using maximum-likelihood Heckman selection models. In all of these models, the outcome equation has the same specification as the corresponding OLS model in Table 2; in each model, the selection equation contained a single predictor-Catholic affiliation-which was positively and significantly associated with the case being selected in all instances $\left(p_{\mathrm{s}}<0.001\right)$. These results are summarized in Table A4. The key results in these models were largely comparable to those in Table 2 . The Ideology $\times$ Catholic interaction was positive and significant in Model $1(b=0.15, p<0.001)$ and Model $3(b=0.12, p<0.001)$, while the Religiosity $\times$ Catholic interaction was positive and significant in Model $2(b=0.15, p<0.001)$ and Model $3(b=0.12$,

\footnotetext{
${ }^{10}$ As an additional check, the cross-partial derivatives for the two interactions in Model 3 were also computed for the probability of giving the most positive evaluative response to Pope Francis (Karaca-Mandic et al. 2012). These estimates indicate the difference in the marginal probability effects for ideology and religiosity between non-Catholics and Catholics (with respect to the top evaluative category). For the Ideology $\times$ Catholic interaction, the cross-partial effect was 0.23 $(S E=0.09, p=0.008)$. For the Religiosity $\times$ Catholic interaction, the cross-partial effect was 0.36 $(S E=0.08, p<0.001)$. These results thus confirm the conventional interaction tests presented above.
} 
$p<0.001)$. Conditional effects for each predictor were computed based on the estimates from Model 3. Breaking down the first interaction, the relationship between ideology and evaluations of Francis was negative and significant among non-Catholics $(b=-0.11, S E=0.02, p<0.001)$ but indistinguishable from zero among Catholics $(b=0.01, S E=0.03, p>0.250)$. Looking at the second interaction, religiosity was unrelated to evaluations of Francis among non-Catholics $(b=0.02$, $S E=0.02, p>0.250)$ but predicted more positive impressions of the pontiff among Catholics $(b=0.14$, $S E=0.03, p<0.001)$.

Thus, both sets of alternative analyses produced results similar to those reported in Table 2, continuing to provide support for Hypothesis 2. 
Table A3. Evaluation of Pope Francis as a Function of Political Ideology, Religiosity, and Denomination, 2015 Pew (Ordinal Logit)

\begin{tabular}{|c|c|c|c|c|c|c|c|c|c|}
\hline \multirow[b]{2}{*}{ Predictor } & \multicolumn{3}{|c|}{ Model 1} & \multicolumn{3}{|c|}{ Model 2} & \multicolumn{3}{|c|}{ Model 3} \\
\hline & $b$ & $95 \% C I$ & $p$ & $b$ & $95 \% C I$ & $p$ & $b$ & $95 \% C I$ & $p$ \\
\hline Age & 0.79 & {$[0.50,1.08]$} & $<0.001$ & 0.80 & {$[0.51,1.09]$} & $<0.001$ & 0.79 & {$[0.50,1.09]$} & $<0.001$ \\
\hline Income & 0.22 & {$[-0.05,0.50]$} & 0.121 & 0.25 & {$[-0.03,0.54]$} & 0.081 & 0.25 & {$[-0.04,0.53]$} & 0.089 \\
\hline White (1 = yes) & 0.08 & {$[-0.11,0.27]$} & $>0.250$ & 0.07 & {$[-0.12,0.26]$} & $>0.250$ & 0.07 & {$[-0.12,0.26]$} & $>0.250$ \\
\hline Education & 0.19 & {$[-0.10,0.48]$} & 0.196 & 0.21 & {$[-0.08,0.50]$} & 0.162 & 0.19 & {$[-0.10,0.48]$} & 0.197 \\
\hline Male (1 = yes) & -0.11 & {$[-0.27,0.05]$} & 0.183 & -0.10 & {$[-0.26,0.06]$} & 0.209 & -0.10 & {$[-0.26,0.06]$} & 0.220 \\
\hline Catholic $(1=$ yes $)$ & 0.30 & {$[-0.13,0.73]$} & 0.173 & -0.28 & {$[-0.86,0.30]$} & $>0.250$ & -0.61 & {$[-1.23,0.01]$} & 0.053 \\
\hline Religiosity & 0.47 & {$[0.18,0.77]$} & 0.002 & 0.21 & {$[-0.10,0.51]$} & 0.187 & 0.29 & {$[-0.03,0.60]$} & 0.074 \\
\hline Partisanship & -0.49 & {$[-0.72,-0.25]$} & $<0.001$ & -0.48 & {$[-0.72,-0.24]$} & $<0.001$ & -0.49 & {$[-0.73,-0.25]$} & $<0.001$ \\
\hline Ideology & -1.13 & {$[-1.56,-0.70]$} & $<0.001$ & -0.82 & {$[-1.21,-0.43]$} & $<0.001$ & -1.05 & {$[-1.48,-0.61]$} & $<0.001$ \\
\hline Ideology $\times$ Catholic & 1.47 & {$[0.73,2.20]$} & $<0.001$ & -- & -- & -- & 1.10 & {$[0.32,1.87]$} & 0.006 \\
\hline Religiosity $\times$ Catholic & -- & -- & -- & 1.95 & {$[1.16,2.74]$} & $<0.001$ & 1.59 & {$[0.78,2.41]$} & $<0.001$ \\
\hline Cut 1 & -2.75 & {$[-3.11,-2.37]$} & & -2.72 & {$[-3.09,-2.36]$} & & -2.81 & {$[-3.18,-2.44]$} & \\
\hline Cut 2 & -1.75 & {$[-3.07,-1.42]$} & & -1.73 & {$[-2.05,-1.41]$} & & -1.81 & {$[-2.14,-1.49]$} & \\
\hline Cut 3 & 0.78 & {$[0.47,1.10]$} & & 0.80 & {$[0.49,1.11]$} & & 0.72 & {$[0.40,1.04]$} & \\
\hline$F(\mathrm{df})$ & \multirow{2}{*}{\multicolumn{3}{|c|}{$\begin{array}{c}27.44(10,3263), p<0.001 \\
3,273\end{array}$}} & \multirow{2}{*}{\multicolumn{3}{|c|}{$\begin{array}{c}26.09(10,3263), p<0.001 \\
3,273\end{array}$}} & \multirow{2}{*}{\multicolumn{3}{|c|}{$\begin{array}{c}25.50(11,3262), p<0.001 \\
3,273\end{array}$}} \\
\hline$N$ & & & & & & & & & \\
\hline
\end{tabular}

Note. Entries are ordinal logit coefficients. Survey weights are applied. 
Table A4. Evaluation of Pope Francis as a Function of Political Ideology, Religiosity, and Denomination, 2015 Pew (Heckman Selection Model)

\begin{tabular}{|c|c|c|c|c|c|c|c|c|c|}
\hline \multirow[b]{2}{*}{ Predictor } & \multicolumn{3}{|c|}{ Model 1} & \multicolumn{3}{|c|}{ Model 2} & \multicolumn{3}{|c|}{ Model 3} \\
\hline & $b$ & $95 \% C I$ & $p$ & $b$ & $95 \% C I$ & $p$ & $b$ & $95 \% C I$ & $p$ \\
\hline Age & 0.07 & {$[0.04,0.10]$} & $<0.001$ & 0.07 & {$[0.04,0.10]$} & $<0.001$ & 0.07 & {$[0.04,0.10]$} & $<0.001$ \\
\hline Income & 0.03 & {$[0.01,0.06]$} & 0.021 & 0.04 & {$[0.01,0.06]$} & 0.014 & 0.03 & {$[0.01,0.06]$} & 0.016 \\
\hline White (1 = yes) & 0.01 & {$[-0.01,0.03]$} & $>0.250$ & 0.01 & {$[-0.01,0.03]$} & $>0.250$ & 0.01 & {$[-0.01,0.03]$} & $>0.250$ \\
\hline Education & 0.03 & {$[-0.001,0.06]$} & 0.062 & 0.03 & {$[0.0002,0.06]$} & 0.048 & 0.03 & {$[-0.002,0.06]$} & 0.064 \\
\hline Male $(1=$ yes $)$ & -0.01 & {$[-0.03,0.01]$} & 0.185 & -0.01 & {$[-0.03,0.01]$} & 0.197 & -0.01 & {$[-0.03,0.01]$} & 0.212 \\
\hline Catholic $(1=$ yes $)$ & 0.03 & {$[-0.01,0.07]$} & 0.166 & -0.005 & {$[-0.05,0.04]$} & $>0.250$ & -0.04 & {$[-0.09,0.01]$} & 0.123 \\
\hline Religiosity & 0.03 & {$[0.004,0.06]$} & 0.028 & 0.01 & {$[-0.02,0.04]$} & $>0.250$ & 0.02 & {$[-0.01,0.05]$} & $>0.250$ \\
\hline Partisanship & -0.04 & {$[-0.07,-0.02]$} & $<0.001$ & -0.04 & {$[-0.07,-0.02]$} & $<0.001$ & -0.04 & {$[-0.07,-0.02]$} & $<0.001$ \\
\hline Ideology & -0.11 & {$[-0.16,-0.07]$} & $<0.001$ & -0.08 & {$[-0.12,-0.04]$} & $<0.001$ & -0.11 & {$[-0.15,-0.06]$} & $<0.001$ \\
\hline Ideology $\times$ Catholic & 0.15 & {$[0.08,0.21]$} & $<0.001$ & -- & -- & -- & 0.12 & {$[0.05,0.19]$} & 0.001 \\
\hline Religiosity $\times$ Catholic & -- & -- & -- & 0.15 & {$[0.09,0.22]$} & $<0.001$ & 0.12 & {$[0.05,0.18]$} & 0.001 \\
\hline Intercept & 0.52 & {$[0.49,0.56]$} & $<0.001$ & 0.52 & {$[0.49,0.55]$} & $<0.001$ & 0.53 & {$[0.50,0.56]$} & $<0.001$ \\
\hline$F(\mathrm{df})$ & \multirow{3}{*}{\multicolumn{3}{|c|}{$\begin{array}{c}32.09(10,4524), p<0.00 \\
4,534 \\
-0.000003(0.000001)\end{array}$}} & \multirow{3}{*}{\multicolumn{3}{|c|}{$\begin{array}{c}33.34(10,4524), p<0.001 \\
4,534 \\
-0.000004(0.000001)\end{array}$}} & \multirow{3}{*}{\multicolumn{3}{|c|}{$\begin{array}{c}32.16(11,4523), p<0.001 \\
4,534 \\
-0.000004(0.000001)\end{array}$}} \\
\hline$N$ & & & & & & & & & \\
\hline$\rho(\mathrm{SE})$ & & & & & & & & & \\
\hline
\end{tabular}

Note. Entries are coefficients from the regression equations of maximum-likelihood Heckman selection models. In all models, the selection equation contains a single predictor - Catholic affiliation — which was positively and significantly associated with the case being selected in all instances $(p s<0.001)$. Survey weights are applied. 


\section{Tests of Hypothesis 2 in the 2018 Pew Survey}

Since only the 2015 Pew and 2016 ANES surveys contained complete, multiple-item measures of religiosity, I restrict my analysis of Hypothesis 2 to these datasets in the main body of the paper. However, for completeness, I repeated the Hypotheses 2 analyses summarized in Tables 2 and 3 in the 2018 Pew data, with the single-item religious-attendance measure substituted for religiosity. Otherwise, these analyses were identical in specification to those reported in Table 2 . The results are summarized in Table A5, which shows OLS estimates with survey weights applied.

The key results in these models were largely comparable to those in Table 3, though weaker for the interaction between ideology and Catholic affiliation. The Ideology $\times$ Catholic interaction was positive but not significant in Model $1(b=0.09, p=0.153)$ or Model $3(b=0.07, p>0.250)$, though the Attendance $\times$ Catholic interaction was positive and significant in Model $2(b=0.13, p=0.015)$ and Model 3 ( $b=0.12, p=0.028)$. Given that the signs of the interactions were consistent with Hypothesis 2 , both interactions were probed in post-hoc tests similar to those conducted for the analyses in Table 3. With respect to the Ideology $\times$ Catholic interaction, the relationship between ideology and evaluations of Francis was negative and marginally significant among non-Catholics $(b=-0.09$, $S E=0.05, p=0.061)$ but small and nonsignificant among Catholics $(b=-0.01, S E=0.06, p>0.250)$. With respect to the Attendance $\times$ Catholic interaction, attendance was unrelated to evaluations of Francis among non-Catholics $(b=-0.02, S E=0.03, p>0.250)$ but associated with more positive impressions of the pope among Catholics $(b=0.10, S E=0.04, p=0.023)$. These patterns of interaction are plotted in Figure A1.

Since the Francis evaluation scale in the 2018 Pew study also used an ordinal scale, the models in Table A5 were re-estimated using ordinal logit. These results are summarized in Table A6. Again, the results were similar. The Ideology $\times$ Catholic interaction was positive but failed to reach significance in Model $1(b=0.99, p=0.155)$ and Model $3(b=0.77, p>0.250)$, whereas the Attendance $\times$ Catholic interaction was positive and significant in Model $2(b=1.45, p=0.007)$ and Model 3 $(b=1.34, p=0.012) .{ }^{11}$ To follow up on this, discrete probability changes for ideology and attendance were computed for non-Catholics and Catholics based on average marginal effects. As in Table A4 above, these analyses focused on the probability of responding in the highest (i.e., most positive) evaluative category on the ordinal Francis measure. The estimates from Model 3 in Table A6 were used in these computations. For the Ideology $\times$ Catholic interaction, these analyses indicated that going from the most left-wing to the most right-wing position on the ideology scale was associated with a marginally-significant decline in the probability of giving Francis the most positive response among non-Catholics $(\Delta p=-0.15, S E=0.08, p=0.056)$, while being essentially unrelated to shifts in the probability of giving the most positive evaluation among Catholics $(\Delta p=-0.01, S E=0.16$, $p>0.250)$. To examine the Attendance $\times$ Catholic interaction, similar discrete probability changes were computed for a shift from the lowest to highest frequency of attendance. The analyses

\footnotetext{
${ }^{11}$ The cross-partial derivatives for the two interactions in Model 3 in Table A6 were also computed for the probability of giving the most positive evaluative response to Pope Francis. Again, these estimates indicate the difference in the marginal probability effects for ideology and attendance between non-Catholics and Catholics (with response to the top evaluative category). For the Ideology $\times$ Catholic interaction, the cross-partial effect was $0.14(S E=0.16, p>0.250)$. For the Attendance $\times$ Catholic interaction, the cross-partial effect was 0.31 (SE=0.11, $p=0.007)$. Again, these estimates confirm the conventional interaction tests presented above.
} 
indicated that a shift from the lowest to the highest attendance frequency was associated with little change in the probability of giving Francis the highest possible evaluation among non-Catholics $(\Delta p=-0.03, S E=0.05, p>0.250)$, whereas the same shift in religiosity was associated a much larger increase in the probability of giving the most positive response to Francis among Catholics $(\Delta p=0.27, S E=0.10, p=0.007)$. Thus, the ordinal logit results for Hypothesis 2 in the 2018 Pew are similar to the corresponding OLS results.

Like its counterpart in the 2015 Pew survey, the Francis evaluation in the 2018 Pew was marred by a high level of non-response. To deal with possible sample selection, the models in Table A5 were re-estimated using maximum-likelihood Heckman selection models. In all of these models, the outcome equation has the same specification as the corresponding OLS model in Table A5; in each model, the selection equation contained a single predictor-Catholic affiliation-which was positively and significantly associated with the case being selected in all instances (ps $<0.001)$. The results of these analyses are shown in Table A7. The findings were similar to those in the OLS models reported in Table A5. The Ideology $\times$ Catholic interaction was positive but nonsignificant in Model $1(b=0.09, p=0.153)$ and Model $3(b=0.07, p>0.250)$, while the Attendance $\times$ Catholic interaction was positive and significant in Model $2(b=0.13, p=0.015)$ and Model $3(b=0.12$, $p=0.028)$. Conditional effects for each predictor were computed based on the estimates from Model 3 in Table A7. Breaking down the Ideology $\times$ Catholic interaction, the relationship between ideology and evaluations of Francis was negative and significant among non-Catholics $(b=-0.09, S E=0.05$, $p=0.061)$. However, it was small and failed to reach significance among Catholics $(b=-0.01$, $S E=0.06, p>0.250)$. With respect to the Attendance $\times$ Catholic interaction, frequency of attendance was unrelated to evaluations of Francis among non-Catholics $(b=-0.02, S E=0.03, p>0.250)$, whereas it was associated with more positive evaluations of Francis among Catholics $(b=0.10, S E=0.04$, $p=0.023)$.

In sum, the pattern of results in the 2018 Pew were broadly consistent with Hypothesis 2, though weaker with respect to ideology. 
POPE FRANCIS - 51

Table A5: Evaluation of Pope Francis as a Function of Political Ideology, Attendance, and Denomination (2018 Pew)

\begin{tabular}{|c|c|c|c|c|c|c|c|c|c|}
\hline \multirow[b]{2}{*}{ Predictor } & \multicolumn{3}{|c|}{ Model 1} & \multicolumn{3}{|c|}{ Model 2} & \multicolumn{3}{|c|}{ Model 3} \\
\hline & $b$ & $95 \% C I$ & $p$ & $b$ & $95 \% C I$ & $p$ & $b$ & $95 \% C I$ & $p$ \\
\hline Age & 0.004 & {$[-0.06,0.08]$} & $>0.250$ & 0.01 & {$[-0.06,0.08]$} & $>0.250$ & 0.005 & {$[-0.07,0.08]$} & $>0.250$ \\
\hline Income & -0.00004 & {$[-0.05,0.05]$} & $>0.250$ & 0.001 & {$[-0.05,0.05]$} & $>0.250$ & 0.001 & {$[-0.05,0.05]$} & $>0.250$ \\
\hline White $(1=$ yes $)$ & 0.06 & {$[0.03,0.09]$} & 0.001 & 0.06 & {$[0.02,0.09]$} & 0.001 & 0.06 & {$[0.02,0.09]$} & 0.001 \\
\hline Education & 0.03 & {$[-0.03,0.08]$} & $>0.250$ & 0.03 & {$[-0.03,0.08]$} & $>0.250$ & 0.02 & {$[-0.03,0.08]$} & $>0.250$ \\
\hline Male $(1=$ yes $)$ & -0.01 & {$[-0.04,0.02]$} & $>0.250$ & -0.01 & {$[-0.04,0.02]$} & $>0.250$ & -0.01 & {$[-0.04,0.02]$} & $>0.250$ \\
\hline Catholic $(1=$ yes $)$ & 0.06 & {$[-0.01,0.13]$} & 0.083 & 0.04 & {$[-0.02,0.11]$} & 0.192 & 0.01 & {$[-0.07,0.09]$} & $>0.250$ \\
\hline Attendance & -0.0003 & {$[-0.05,0.05]$} & $>0.250$ & -0.02 & {$[-0.08,0.04]$} & $>0.250$ & -0.02 & {$[-0.08,0.04]$} & $>0.250$ \\
\hline Partisanship & -0.11 & {$[-0.15,-0.06]$} & $<0.001$ & -0.11 & {$[-0.15,-0.06]$} & $<0.001$ & -0.11 & {$[-0.15,-0.06]$} & $<0.001$ \\
\hline Ideology & -0.09 & {$[-0.19,-0.001]$} & 0.048 & -0.07 & {$[-0.15,0.01]$} & 0.088 & -0.09 & {$[-0.18,0.004]$} & 0.061 \\
\hline Ideology $\times$ Catholic & 0.09 & {$[-0.03,0.22]$} & 0.153 & -- & -- & -- & 0.07 & {$[-0.06,0.20]$} & $>0.250$ \\
\hline Attendance $\times$ Catholic & -- & -- & -- & 0.13 & {$[0.02,0.23]$} & 0.015 & 0.12 & {$[0.01,0.22]$} & 0.028 \\
\hline Intercept & 0.53 & {$[0.46,0.59]$} & $<0.001$ & 0.53 & {$[0.47,0.59]$} & $<0.001$ & 0.54 & {$[0.47,0.60]$} & $<0.001$ \\
\hline$F(\mathrm{df})$ & \multicolumn{3}{|c|}{$12.30(10,1098), p<0.001$} & \multicolumn{3}{|c|}{$13.03(10,1098), p<0.001$} & \multicolumn{3}{|c|}{$12.14(11,1097), p<0.001$} \\
\hline $\mathrm{R}^{2}$ & \multicolumn{3}{|c|}{0.116} & \multicolumn{3}{|c|}{0.118} & \multicolumn{3}{|c|}{0.119} \\
\hline$N$ & \multicolumn{3}{|c|}{1,108} & \multicolumn{3}{|c|}{1,108} & \multicolumn{3}{|c|}{3,273} \\
\hline
\end{tabular}

Note. Entries are ordinary least-squares regression coefficients. Survey weights are applied. 

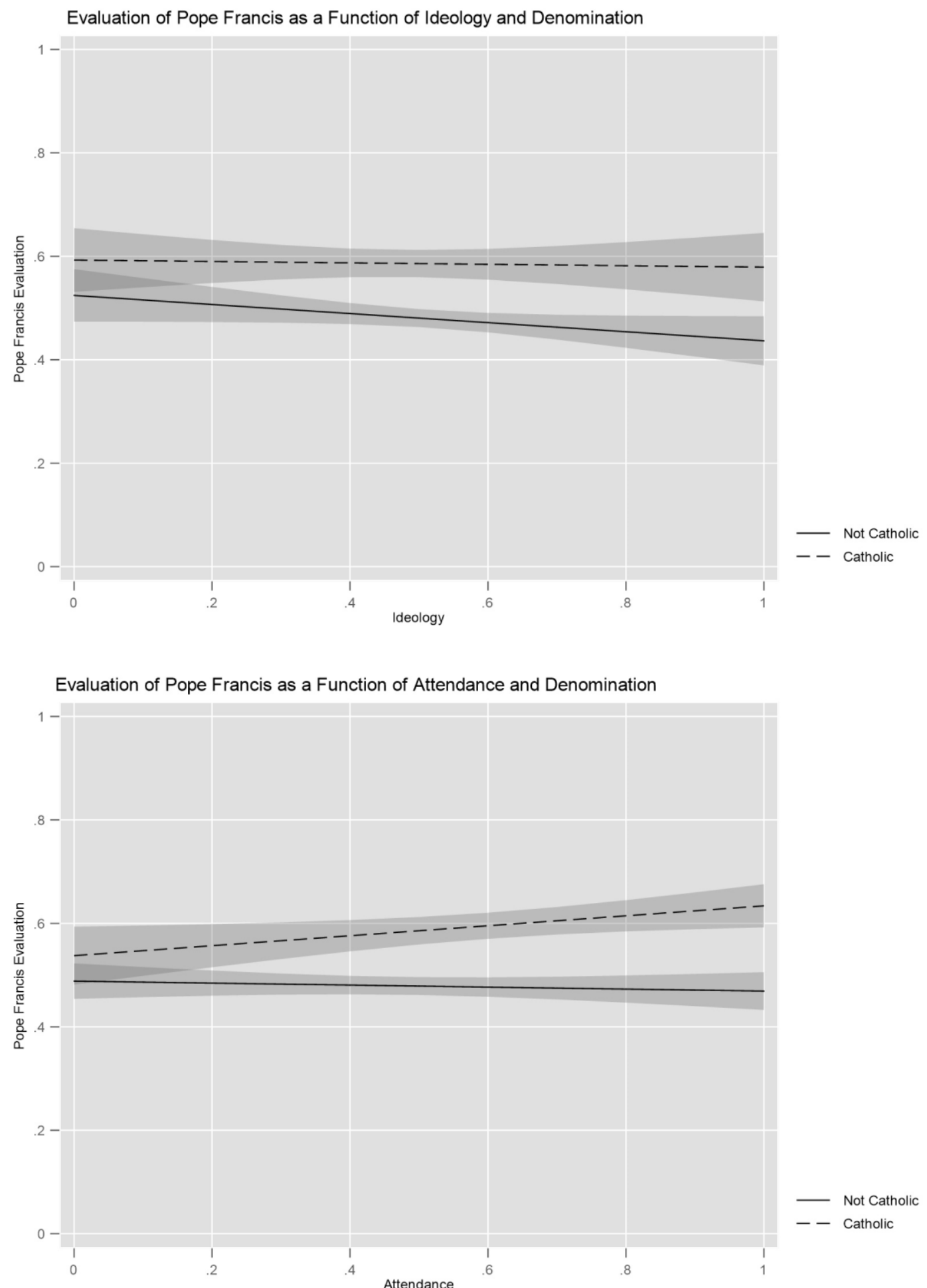

Figure A1: Evaluation of Pope Francis as a function of political ideology, religiosity, and denomination. Predicted values based on estimates from Model 3 in Table A5. (2018 Pew) 
Table A6. Evaluation of Pope Francis as a Function of Political Ideology, Attendance, and Denomination, 2018 Pew (Ordinal Logit)

\begin{tabular}{|c|c|c|c|c|c|c|c|c|c|}
\hline \multirow[b]{2}{*}{ Predictor } & \multicolumn{3}{|c|}{ Model 1} & \multicolumn{3}{|c|}{ Model 2} & \multicolumn{3}{|c|}{ Model 3} \\
\hline & $b$ & $95 \% C I$ & $p$ & $b$ & $95 \% C I$ & $p$ & $b$ & $95 \% C I$ & $p$ \\
\hline Age & 0.20 & {$[-0.48,0.88]$} & $>0.250$ & 0.21 & {$[-0.47,0.89]$} & $>0.250$ & 0.20 & {$[-0.48,0.87]$} & $>0.250$ \\
\hline Income & -0.06 & {$[-0.55,0.43]$} & $>0.250$ & -0.04 & {$[-0.54,0.46]$} & $>0.250$ & -0.05 & {$[-0.54,0.45]$} & $>0.250$ \\
\hline White (1 = yes) & 0.53 & {$[0.22,0.85]$} & 0.001 & 0.53 & {$[0.21,0.85]$} & 0.001 & 0.52 & {$[0.21,0.84]$} & 0.001 \\
\hline Education & 0.16 & {$[-0.36,0.67]$} & $>0.250$ & 0.17 & {$[-0.35,0.68]$} & $>0.250$ & 0.15 & {$[-0.37,0.67]$} & $>0.250$ \\
\hline Male (1 = yes) & -0.06 & {$[-0.34,0.21]$} & $>0.250$ & -0.08 & {$[-0.36,0.20]$} & $>0.250$ & -0.08 & {$[-0.36,0.19]$} & $>0.250$ \\
\hline Catholic $(1=$ yes $)$ & 0.53 & {$[-0.22,1.29]$} & 0.168 & 0.28 & {$[-0.35,0.91]$} & $>0.250$ & -0.07 & {$[-0.93,0.79]$} & $>0.250$ \\
\hline Attendance & 0.05 & {$[-0.43,0.52]$} & $>0.250$ & -0.22 & {$[-0.75,0.32]$} & $>0.250$ & -0.18 & {$[-0.72,0.37]$} & $>0.250$ \\
\hline Partisanship & -0.98 & {$[-1.41,-0.44]$} & $<0.001$ & -0.95 & {$[-1.38,-0.52]$} & $<0.001$ & -0.95 & {$[-1.38,-0.52]$} & $<0.001$ \\
\hline Ideology & -0.87 & {$[-1.70,-0.04]$} & 0.041 & -0.64 & {$[-1.41,0.13]$} & 0.104 & -0.81 & {$[-1.64,0.02]$} & 0.056 \\
\hline Ideology $\times$ Catholic & 0.99 & {$[-0.37,2.35]$} & 0.155 & -- & -- & -- & 0.77 & {$[-0.60,2.13]$} & $>0.250$ \\
\hline Attendance $\times$ Catholic & -- & -- & -- & 1.45 & {$[0.40,2.51]$} & 0.007 & 1.34 & {$[0.30,2.38]$} & 0.012 \\
\hline Cut 1 & -2.83 & {$[-3.48,-2.17]$} & & -2.81 & {$[-3.44,-2.18]$} & & -2.91 & {$[-3.57,-2.24]$} & \\
\hline Cut 2 & -1.57 & {$[-2.18,-0.96]$} & & -1.56 & {$[-2.15,-0.96]$} & & -1.65 & {$[-2.27,-1.02]$} & \\
\hline Cut 3 & 0.65 & {$[0.06,1.25]$} & & 0.67 & {$[0.08,1.25]$} & & 0.58 & {$[-0.03,1.19]$} & \\
\hline$F(\mathrm{df})$ & \multirow{2}{*}{\multicolumn{3}{|c|}{$\begin{array}{c}9.60(10,1098), p<0.001 \\
1,108\end{array}$}} & \multirow{2}{*}{\multicolumn{3}{|c|}{$\begin{array}{c}9.97(10,1098), p<0.001 \\
1,108\end{array}$}} & \multirow{2}{*}{\multicolumn{3}{|c|}{$\begin{array}{c}9.23(11,1097), p<0.001 \\
1,108\end{array}$}} \\
\hline$N$ & & & & & & & & & \\
\hline
\end{tabular}

Note. Entries are ordinal logit coefficients. Survey weights are applied. 
Table A7. Evaluation of Pope Francis as a Function of Political Ideology, Attendance, and Denomination, 2018 Pew (Heckman Selection Model)

\begin{tabular}{|c|c|c|c|c|c|c|c|c|c|}
\hline \multirow[b]{2}{*}{ Predictor } & \multicolumn{3}{|c|}{ Model 1} & \multicolumn{3}{|c|}{ Model 2} & \multicolumn{3}{|c|}{ Model 3} \\
\hline & $b$ & $95 \% C I$ & $p$ & $b$ & $95 \% C I$ & $p$ & $b$ & $95 \% C I$ & $p$ \\
\hline Age & 0.004 & {$[-0.07,0.08]$} & $>0.250$ & 0.01 & {$[-0.07,0.08]$} & $>0.250$ & 0.005 & {$[-0.07,0.08]$} & $>0.250$ \\
\hline Income & -0.00004 & {$[-0.05,0.05]$} & $>0.250$ & 0.001 & {$[-0.05,0.05]$} & $>0.250$ & 0.001 & {$[-0.05,0.05]$} & $>0.250$ \\
\hline White $(1=$ yes $)$ & 0.06 & {$[0.03,0.09]$} & 0.001 & 0.06 & {$[0.02,0.09]$} & 0.001 & 0.06 & {$[0.02,0.09]$} & 0.001 \\
\hline Education & 0.03 & {$[-0.03,0.08]$} & $>0.250$ & 0.03 & {$[-0.03,0.08]$} & $>0.250$ & 0.02 & {$[-0.03,0.08]$} & $>0.250$ \\
\hline Male $(1=$ yes $)$ & -0.01 & {$[-0.04,0.02]$} & $>0.250$ & -0.01 & {$[-0.04,0.02]$} & $>0.250$ & -0.01 & {$[-0.04,0.02]$} & $>0.250$ \\
\hline Catholic $(1=$ yes $)$ & 0.06 & {$[-0.01,0.13]$} & 0.083 & 0.04 & {$[-0.02,0.11]$} & 0.191 & 0.01 & {$[-0.07,0.09]$} & $>0.250$ \\
\hline Attendance & -0.0003 & {$[-0.05,0.05]$} & $>0.250$ & -0.02 & {$[-0.08,0.04]$} & $>0.250$ & -0.02 & {$[-0.08,0.04]$} & $>0.250$ \\
\hline Partisanship & -0.11 & {$[-0.15,-0.06]$} & $<0.001$ & -0.11 & {$[-0.15,-0.06]$} & $<0.001$ & -0.11 & {$[-0.15,-0.06]$} & $<0.001$ \\
\hline Ideology & -0.09 & {$[-0.19,-0.001]$} & 0.048 & -0.07 & {$[-0.15,0.01]$} & 0.088 & -0.09 & {$[-0.18,0.004]$} & 0.061 \\
\hline Ideology $\times$ Catholic & 0.09 & {$[-0.03,0.22]$} & 0.153 & -- & -- & -- & 0.07 & {$[-0.06,0.20]$} & $>0.250$ \\
\hline Attendance $\times$ Catholic & -- & -- & -- & 0.13 & {$[0.02,0.23]$} & 0.015 & 0.12 & {$[0.01,0.22]$} & 0.028 \\
\hline Intercept & 0.53 & {$[0.46,0.59]$} & $<0.001$ & 0.53 & {$[0.47,0.59]$} & $<0.001$ & 0.54 & {$[0.47,0.60]$} & $<0.001$ \\
\hline$F(\mathrm{df})$ & \multirow{3}{*}{\multicolumn{3}{|c|}{$\begin{array}{c}12.33(10,1353), p<0.0 \\
1,363 \\
-0.00001(0.00001)\end{array}$}} & \multirow{3}{*}{\multicolumn{3}{|c|}{$\begin{array}{c}13.05(10,1353), p<0.00 \\
1,363 \\
-0.00001(0.00001)\end{array}$}} & \multirow{3}{*}{\multicolumn{3}{|c|}{$\begin{array}{c}12.16(11,1352), p<0.00 \\
1,363 \\
-0.00001(0.00001)\end{array}$}} \\
\hline$N$ & & & & & & & & & \\
\hline$\rho(\mathrm{SE})$ & & & & & & & & & \\
\hline
\end{tabular}

Note. Entries are coefficients from the regression equations of maximum-likelihood Heckman selection models. In all models, the selection equation contains a single predictor-Catholic affiliation — which was positively and significantly associated with the case being selected in all instances $(p s<0.001)$. Survey weights are applied. 


\section{Primary Models with Additional Covariates}

To provide further evidence of the key results reported in the text of the paper, I reestimated selectedmodels reported in Tables 1-4 with a number of additional covariates included. These included: (1) a dummy variable for whether the respondent was evangelical (all surveys), given that members of this especially-conservative denominational group may have unfavorable views of Pope Francis; (2) a dummy variable for whether the respondent was Latino (all surveys), given that possibility that Latino respondents may be more favorably disposed to a Latin American pope; (3) a dummy variable for whether the respondent was married (all surveys); (4) a dummy variable for whether the respondent lived in a Southern state (all surveys); and (5) dummy variables for urban and suburban residence, with rural residence as the reference group (2018 Pew only).

Replications of the models presented in Table 1 with all additional covariates available in the relevant dataset are reported in Tables A8 (2015 Pew), A9 (2016 ANES), and A10 (2018 Pew). The key estimates for ideology are substantively similar to those in Table 1 across all surveys. Thus, Hypothesis 1 continues to receive support in these models. Moreover, most of the coefficients for the added covariates fail to reach significance. The only exception to this is the evangelical dummy, which is significant and negative in the 2015 Pew and 2016 ANES. These estimates suggest that evangelical Protestants, net of other factors, had slightly more negative feelings about Pope Francis.

In turn, Table A11 provides replications of Model 2 from Tables 2 and 3 with all additional covariates available in the relevant dataset. Estimates for the 2015 Pew are in the left columns, while estimates for the 2016 ANES are in the right columns. Again, the estimates reported in Table A11 are substantively identical to those in Tables 2 and 3 . As such, these results provide continued support for Hypotheses $2 \mathrm{a}$ and $2 \mathrm{~b}$.

Finally, Table A12 provides replications of the two models from Table 4 for the 2016 ANES, with dummy variables for whether the respondent was evangelical, Latino, married, and living in the South included. Inclusion of these additional covariates did not change the substantive conclusions of the original analyses reported in Table 4; Hypothesis 3 continues to receive support. 
Table A8: Evaluation of Pope Francis as a Function of Political Ideology, with Additional Covariates (2015 Pew)

\begin{tabular}{|c|c|c|c|c|c|c|}
\hline \multirow[b]{2}{*}{ Predictor } & \multicolumn{3}{|c|}{ Model 1} & \multicolumn{3}{|c|}{ Model 2} \\
\hline & $b$ & $95 \% C I$ & $p$ & $b$ & $95 \% C I$ & $p$ \\
\hline Age & 0.08 & {$[0.05,0.11]$} & $<0.001$ & 0.08 & {$[0.05,0.11]$} & $<0.001$ \\
\hline Income & 0.04 & {$[0.01,0.07]$} & 0.023 & 0.05 & {$[0.01,0.08]$} & 0.005 \\
\hline Married (1 = yes) & -0.01 & {$[-0.03,0.004]$} & 0.124 & -0.01 & {$[-0.03,0.003]$} & 0.105 \\
\hline Live in South (1 = yes) & 0.01 & {$[-0.01,0.03]$} & $>0.250$ & 0.01 & {$[-0.01,0.02]$} & $>0.250$ \\
\hline White $(1=$ yes $)$ & 0.004 & {$[-0.02,0.03]$} & $>0.250$ & 0.01 & {$[-0.01,0.04]$} & $>0.250$ \\
\hline Latino (1 = yes) & 0.002 & {$[-0.03,0.04]$} & $>0.250$ & 0.01 & {$[-0.03,0.04]$} & $>0.250$ \\
\hline Education & 0.03 & {$[0.002,0.06]$} & 0.034 & 0.03 & {$[-0.01,0.06]$} & 0.102 \\
\hline Male (1 = yes) & -0.02 & {$[-0.04,-0.003]$} & 0.020 & -0.02 & {$[-0.03,0.001]$} & 0.063 \\
\hline Evangelical (1 = yes) & -0.04 & {$[-0.07,-0.02]$} & 0.001 & -0.04 & {$[-0.07,-0.02]$} & 0.002 \\
\hline Catholic (1 = yes) & 0.08 & {$[0.06,0.10]$} & $<0.001$ & 0.08 & {$[0.06,0.10]$} & $<0.001$ \\
\hline Religiosity & 0.05 & {$[0.02,0.09]$} & 0.003 & 0.06 & {$[0.02,0.09]$} & 0.001 \\
\hline Ideology & -0.10 & {$[-0.13,-0.06]$} & $<0.001$ & -0.07 & {$[-0.11,-0.03]$} & 0.001 \\
\hline Partisanship & -- & -- & -- & -0.05 & {$[-0.07,-0.02]$} & $<0.001$ \\
\hline Intercept & 0.50 & {$[0.47,0.54]$} & $<0.001$ & 0.50 & {$[0.46,0.54]$} & $<0.001$ \\
\hline$F(\mathrm{df})$ & \multirow{3}{*}{\multicolumn{3}{|c|}{$\begin{array}{c}19.62(12,2952), p<0.001 \\
0.090 \\
2,964\end{array}$}} & \multirow{3}{*}{\multicolumn{3}{|c|}{$\begin{array}{c}19.49(13,2906), p<0.001 \\
0.097 \\
2.919\end{array}$}} \\
\hline $\mathrm{R}^{2}$ & & & & & & \\
\hline$N$ & & & & & & \\
\hline
\end{tabular}

Note. Entries are ordinary least-squares regression coefficients. Survey weights are applied. 
Table A9: Evaluation of Pope Francis as a Function of Political Ideology, with Additional Covariates (2016 ANES)

\begin{tabular}{|c|c|c|c|c|c|c|}
\hline \multirow[b]{2}{*}{ Predictor } & \multicolumn{3}{|c|}{ Model 1} & \multicolumn{3}{|c|}{ Model 2} \\
\hline & $b$ & $95 \% C I$ & $p$ & $b$ & $95 \% C I$ & $p$ \\
\hline Age & 0.24 & {$[0.18,0.30]$} & $<0.001$ & 0.23 & {$[0.18,0.29]$} & $<0.001$ \\
\hline Income & 0.08 & {$[0.03,0.13]$} & 0.003 & 0.08 & {$[0.03,0.13]$} & 0.003 \\
\hline Married $(1=$ yes $)$ & -0.01 & {$[-0.04,0.02]$} & $>0.250$ & -0.01 & {$[-0.04,0.02]$} & $>0.250$ \\
\hline Live in South $(1=$ yes $)$ & -0.002 & {$[-0.03,0.02]$} & $>0.250$ & -0.0001 & {$[-0.02,0.02]$} & $>0.250$ \\
\hline White (1 = yes) & 0.02 & {$[-0.01,0.06]$} & 0.174 & 0.03 & {$[-0.001,0.07]$} & 0.055 \\
\hline Latino $(1=$ yes $)$ & 0.01 & {$[-0.04,0.07]$} & $>0.250$ & 0.01 & {$[-0.04,0.07]$} & $>0.250$ \\
\hline Education & -0.004 & {$[-0.05,0.04]$} & $>0.250$ & -0.004 & {$[-0.05,0.04]$} & $>0.250$ \\
\hline Male $(1=$ yes $)$ & -0.05 & {$[-0.07,-0.03]$} & $<0.001$ & -0.05 & {$[-0.07,-0.03]$} & $<0.001$ \\
\hline Evangelical (1 = yes) & -0.06 & {$[-0.09,-0.02]$} & 0.001 & -0.06 & {$[-0.09,-0.02]$} & 0.001 \\
\hline Catholic (1 = yes) & 0.13 & {$[0.09,0.16]$} & $<0.001$ & 0.13 & {$[0.09,0.16]$} & $<0.001$ \\
\hline Political Engagement & 0.06 & {$[0.01,0.11]$} & 0.019 & 0.06 & {$[0.01,0.11]$} & 0.021 \\
\hline Religiosity & 0.07 & {$[0.03,0.11]$} & 0.001 & 0.07 & {$[0.03,0.11]$} & 0.001 \\
\hline Ideology & -0.20 & {$[-0.25,-0.15]$} & $<0.001$ & -0.15 & {$[-0.21,-0.08]$} & $<0.001$ \\
\hline Partisanship & -- & [ & -- & -0.05 & {$[-0.11,-0.01]$} & 0.017 \\
\hline Intercept & 0.56 & {$[0.49,0.63]$} & $<0.001$ & 0.56 & {$[0.49,0.63]$} & $<0.001$ \\
\hline$F(\mathrm{df})$ & \multirow{3}{*}{\multicolumn{3}{|c|}{$\begin{array}{c}35.26(13,121), p<0.001 \\
0.162 \\
3,126\end{array}$}} & \multirow{2}{*}{\multicolumn{3}{|c|}{$\begin{array}{c}33.02(14,120), p<0.001 \\
0.166\end{array}$}} \\
\hline$R^{2}$ & & & & & & \\
\hline$N$ & & & & \multicolumn{3}{|c|}{2,919} \\
\hline
\end{tabular}

Note. Entries are ordinary least-squares regression coefficients. Survey weights are applied; variance estimates also correct for survey design. 
Table A10: Evaluation of Pope Francis as a Function of Political Ideology, with Additional Covariates (2018 Pew)

\begin{tabular}{|c|c|c|c|c|c|c|}
\hline \multirow[b]{2}{*}{ Predictor } & \multicolumn{3}{|c|}{ Model 1} & \multicolumn{3}{|c|}{ Model 2} \\
\hline & $b$ & $95 \% C I$ & $p$ & $b$ & $95 \% C I$ & $p$ \\
\hline Age & 0.02 & {$[-0.06,0.10]$} & $>0.250$ & 0.01 & {$[-0.07,0.09]$} & $>0.250$ \\
\hline Income & 0.02 & {$[-0.05,0.08]$} & $>0.250$ & 0.03 & {$[-0.03,0.09]$} & $>0.250$ \\
\hline Married $(1=$ yes $)$ & -0.01 & {$[-0.04,0.03]$} & $>0.250$ & -0.01 & {$[-0.04,0.03]$} & $>0.250$ \\
\hline Urban & 0.01 & {$[-0.03,0.06]$} & $>0.250$ & -0.01 & {$[-0.05,0.04]$} & $>0.250$ \\
\hline Suburban & 0.01 & {$[-0.03,0.06]$} & $>0.250$ & 0.001 & {$[-0.04,0.04]$} & $>0.250$ \\
\hline Live in South $(1=$ yes $)$ & 0.01 & {$[-0.03,0.04]$} & $>0.250$ & 0.01 & {$[-0.02,0.04]$} & $>0.250$ \\
\hline White $(1=$ yes $)$ & 0.05 & {$[0.01,0.10]$} & 0.019 & 0.08 & {$[0.03,0.12]$} & 0.001 \\
\hline Latino (1 = yes) & 0.05 & {$[-0.01,0.11]$} & 0.098 & 0.05 & {$[-0.01,0.11]$} & 0.096 \\
\hline Education & 0.06 & {$[0.001,0.12]$} & 0.045 & 0.05 & {$[-0.01,0.11]$} & 0.109 \\
\hline Male (1 = yes) & -0.03 & {$[-0.06,0.01]$} & 0.106 & -0.02 & {$[-0.05,0.01]$} & $>0.250$ \\
\hline Evangelical (1 = yes) & -0.02 & {$[-0.07,0.03]$} & $>0.250$ & -0.02 & {$[-0.07,0.03]$} & $>0.250$ \\
\hline Catholic (1 = yes $)$ & 0.09 & {$[0.05,0.12]$} & $<0.001$ & 0.09 & {$[0.05,0.13]$} & $<0.001$ \\
\hline Attendance & 0.02 & {$[-0.05,0.08]$} & $>0.250$ & 0.02 & {$[-0.04,0.08]$} & $>0.250$ \\
\hline Ideology & -0.14 & {$[-0.22,-0.07]$} & $<0.001$ & -0.05 & {$[-0.14,0.04]$} & $>0.250$ \\
\hline Partisanship & -- & -- & -- & -0.13 & {$[-0.17,-0.08]$} & $<0.001$ \\
\hline Intercept & 0.47 & {$[0.39,0.55]$} & $<0.001$ & 0.46 & {$[0.39,0.54]$} & $<0.001$ \\
\hline$F(\mathrm{df})$ & \multirow{3}{*}{\multicolumn{3}{|c|}{$\begin{array}{c}5.79(14,982), p<0.001 \\
0.096 \\
996\end{array}$}} & \multirow{3}{*}{\multicolumn{3}{|c|}{$8.12(15,968), p<0.001$}} \\
\hline $\mathrm{R}^{2}$ & & & & & & \\
\hline$N$ & & & & & & \\
\hline
\end{tabular}

Note. Entries are ordinary least-squares regression coefficients. Survey weights are applied. For the indicator variables representing urbanicity (Urban and Suburban), the reference group is respondents living in rural areas. 
Table A11: Evaluation of Pope Francis as a Function of Political Ideology, Religiosity, and Denomination, with Additional Covariates (2015 Pew and 2016 ANES)

\begin{tabular}{|c|c|c|c|c|c|c|}
\hline \multirow[b]{2}{*}{ Predictor } & \multicolumn{3}{|c|}{2015 Pew } & \multicolumn{3}{|c|}{2016 ANES } \\
\hline & $b$ & $95 \% C I$ & $p$ & $b$ & $95 \% C I$ & $p$ \\
\hline Age & 0.07 & {$[0.04,0.10]$} & $<0.001$ & 0.23 & {$[0.17,0.29]$} & $<0.001$ \\
\hline Income & 0.05 & {$[0.01,0.08]$} & 0.003 & 0.08 & {$[0.03,0.13]$} & 0.002 \\
\hline Married (1 = yes) & -0.01 & {$[-0.03,0.003]$} & 0.094 & -0.01 & {$[-0.03,0.02]$} & $>0.250$ \\
\hline Live in South $(1=$ yes $)$ & 0.01 & {$[-0.01,0.03]$} & $>0.250$ & -0.001 & {$[-0.02,0.02]$} & $>0.250$ \\
\hline White (1 = yes) & 0.01 & {$[-0.01,0.04]$} & $>0.250$ & 0.03 & {$[-0.001,0.07]$} & 0.056 \\
\hline Latino ( 1 = yes) & 0.01 & {$[-0.02,0.05]$} & $>0.250$ & 0.01 & {$[-0.04,0.07]$} & $>0.250$ \\
\hline Education & 0.02 & {$[-0.01,0.05]$} & 0.115 & 0.002 & {$[-0.05,0.05]$} & $>0.250$ \\
\hline Male $(1=$ yes $)$ & -0.01 & {$[-0.03,0.002]$} & 0.076 & -0.05 & {$[-0.07,-0.03]$} & $<0.001$ \\
\hline Evangelical (1 = yes) & -0.03 & {$[-0.06,-0.004]$} & 0.022 & -0.03 & {$[-0.07,-0.01]$} & 0.021 \\
\hline Catholic (1 = yes) & -0.05 & {$[-0.10,0.01]$} & 0.080 & -0.03 & {$[-0.09,0.03]$} & $>0.250$ \\
\hline Religiosity & 0.05 & {$[-0.01,0.08]$} & 0.019 & 0.04 & {$[-0.001,0.09]$} & 0.057 \\
\hline Partisanship & -0.05 & {$[-0.07,-0.02]$} & $<0.001$ & -0.06 & {$[-0.11,-0.01]$} & 0.014 \\
\hline Ideology & -0.09 & {$[-0.14,-0.05]$} & $<0.001$ & -0.18 & {$[-0.25,-0.11]$} & $<0.001$ \\
\hline Political Engagement & -- & -- & -- & 0.05 & {$[0.003,0.10]$} & 0.037 \\
\hline Ideology $\times$ Catholic & 0.12 & {$[0.05,0.20]$} & $<0.001$ & 0.22 & {$[0.11,0.34]$} & $<0.001$ \\
\hline Religiosity $\times$ Catholic & 0.10 & {$[0.03,0.17]$} & 0.008 & 0.10 & {$[0.01,0.18]$} & 0.028 \\
\hline Intercept & 0.52 & {$[0.48,0.55]$} & $<0.001$ & 0.58 & {$[0.51,0.65]$} & $<0.001$ \\
\hline$F(\mathrm{df})$ & \multicolumn{3}{|c|}{$21.27(15,2904), p<0.001$} & \multicolumn{3}{|c|}{$33.12(16,118), p<0.001$} \\
\hline$R^{2}$ & \multicolumn{3}{|c|}{0.105} & \multicolumn{3}{|c|}{0.178} \\
\hline$N$ & \multicolumn{3}{|c|}{2,919} & \multicolumn{3}{|c|}{3,122} \\
\hline
\end{tabular}

Note. Entries are ordinary least-squares regression coefficients. Survey weights are applied; variance estimates also correct for survey design in the 2016 ANES. 
Table A12: Evaluation of Pope Francis as a Function of Political Ideology and Political Engagement, with Additional Covariates (2016 ANES)

\begin{tabular}{|c|c|c|c|c|c|c|}
\hline \multirow[b]{2}{*}{ Predictor } & \multicolumn{3}{|c|}{ Model 1} & \multicolumn{3}{|c|}{ Model 2} \\
\hline & $b$ & $95 \% C I$ & $p$ & $b$ & $95 \% C I$ & $p$ \\
\hline Age & 0.24 & {$[0.18,0.29]$} & $<0.001$ & 0.23 & {$[0.17,0.29]$} & $<0.001$ \\
\hline Income & 0.08 & {$[0.03,0.13]$} & 0.003 & 0.08 & {$[0.03,0.13]$} & 0.003 \\
\hline Married (1 = yes) & -0.01 & {$[-0.04,0.02]$} & $>0.250$ & -0.01 & {$[-0.04,0.02]$} & $>0.250$ \\
\hline Live in South $(1=$ yes $)$ & -0.0004 & {$[-0.02,0.02]$} & $>0.250$ & -0.002 & {$[-0.03,0.02]$} & $>0.250$ \\
\hline White $(1=$ yes $)$ & 0.03 & {$[-0.01,0.06]$} & 0.116 & 0.03 & {$[-0.01,0.06]$} & 0.126 \\
\hline Latino $(1=$ yes $)$ & 0.01 & {$[-0.05,0.06]$} & $>0.250$ & 0.004 & {$[-0.05,0.06]$} & $>0.250$ \\
\hline Education & -0.01 & {$[-0.06,0.04]$} & $>0.250$ & -0.001 & {$[-0.05,0.05]$} & $>0.250$ \\
\hline Male $(1=$ yes $)$ & -0.05 & {$[-0.07,-0.03]$} & $<0.001$ & -0.05 & {$[-0.07,-0.03]$} & $<0.001$ \\
\hline Evangelical (1 = yes) & -0.05 & {$[-0.09,-0.02]$} & 0.001 & -0.04 & {$[-0.07,-0.004]$} & 0.028 \\
\hline Catholic $(1=$ yes $)$ & 0.13 & {$[0.10,0.16]$} & $<0.001$ & -0.03 & {$[-0.09,0.03]$} & $>0.250$ \\
\hline Religiosity & 0.07 & {$[0.03,0.11]$} & 0.001 & 0.04 & {$[-0.01,0.09]$} & 0.084 \\
\hline Partisanship & -0.05 & {$[-0.09,0.003]$} & 0.065 & -0.05 & {$[-0.10,0.002]$} & 0.062 \\
\hline Ideology & 0.09 & {$[-0.06,0.24]$} & $>0.250$ & 0.07 & {$[-0.08,0.22]$} & $>0.250$ \\
\hline Political Engagement & 0.24 & {$[0.12,0.36]$} & $<0.001$ & 0.25 & {$[0.12,0.37]$} & $<0.001$ \\
\hline Ideology $\times$ Engagement & -0.35 & {$[-0.56,-0.15]$} & 0.001 & -0.37 & {$[-0.58,-0.17]$} & $<0.001$ \\
\hline Ideology $\times$ Catholic & -- & -- & -- & 0.22 & {$[0.11,0.33]$} & $<0.001$ \\
\hline Religiosity $\times$ Catholic & -- & -- & -- & 0.11 & {$[0.02,0.19]$} & 0.014 \\
\hline Intercept & 0.44 & {$[0.33,0.55]$} & $<0.001$ & 0.46 & {$[0.35,0.57]$} & $<0.001$ \\
\hline$F(\mathrm{df})$ & \multirow{3}{*}{\multicolumn{3}{|c|}{$\begin{array}{c}30.22(15,119), p<0.001 \\
0.173 \\
3,122\end{array}$}} & \multirow{3}{*}{\multicolumn{3}{|c|}{$\begin{array}{c}30.55(17,117), f \\
0.186 \\
3,122\end{array}$}} \\
\hline$R^{2}$ & & & & & & \\
\hline$N$ & & & & & & \\
\hline
\end{tabular}

Note. Entries are ordinary least-squares regression coefficients. Survey weights are applied; variance estimates also correct for survey design. 


\section{Predictors of Evaluations of Francis Among Catholics: Full Models (2015 Pew)}

In this section, I provide the full model estimates for the analysis of evaluations of Pope Francis among Catholics from the 2015 Pew survey reported in Figure 4 in the paper. The OLS estimates used to create Figure 14 are shown in Table A14. Given the ordinal nature of the Francis evaluation measure in the 2015 Pew data, I also re-estimated the same model using ordinal logit. These estimates are shown in Table A14. Since there were relatively few missing cases for the Francis measure in the 2015 Pew Catholic subsample, Heckman selection models were not run.

Table A13: Predictors of Evaluations of Pope Francis Among Catholics, 2015 Pew

\begin{tabular}{|c|c|c|c|}
\hline \multirow[b]{2}{*}{ Predictor } & \multicolumn{3}{|c|}{2015 Pew } \\
\hline & $b$ & $95 \% C I$ & $p$ \\
\hline Age & 0.02 & {$[-0.02,0.06]$} & $>0.250$ \\
\hline Income & -0.03 & {$[-0.07,0.01]$} & 0.108 \\
\hline White $(1=$ yes $)$ & 0.02 & {$[-0.02,0.07]$} & $>0.250$ \\
\hline Latino $(1=$ yes $)$ & 0.03 & {$[-0.01,0.08]$} & $>0.250$ \\
\hline Education & 0.03 & {$[-0.01,0.07]$} & 0.179 \\
\hline Male $(1=$ yes $)$ & -0.01 & {$[-0.03,0.02]$} & $>0.250$ \\
\hline Religiosity & 0.13 & {$[0.06,0.20]$} & $<0.001$ \\
\hline Ideology & -0.002 & {$[-0.05,0.06]$} & $>0.250$ \\
\hline Doctrinal Conservatism & -0.05 & {$[-0.09,-0.01]$} & 0.029 \\
\hline Receive Sacraments & -0.01 & {$[-0.04,0.01]$} & $>0.250$ \\
\hline Believe Resurrection & -0.01 & {$[-0.04,0.02]$} & $>0.250$ \\
\hline Help Poor and Needy & 0.05 & {$[0.01,0.09]$} & 0.023 \\
\hline Belong to Parish & 0.01 & {$[-0.02,0.04]$} & $>0.250$ \\
\hline Oppose Abortion & 0.005 & {$[-0.01,0.02]$} & $>0.250$ \\
\hline Open to Children & 0.01 & {$[-0.01,0.04]$} & $>0.250$ \\
\hline Address Climate Change & -0.01 & {$[-0.02,0.01]$} & $>0.250$ \\
\hline Devotion to Mary & 0.02 & {$[-0.01,0.05]$} & 0.178 \\
\hline Relationship with Christ & 0.01 & {$[-0.04,0.06]$} & $>0.250$ \\
\hline Celebrate Feast Days & 0.004 & {$[-0.02,0.03]$} & $>0.250$ \\
\hline Intercept & 0.47 & {$[0.39,0.55]$} & $<0.001$ \\
\hline$F(\mathrm{df})$ & \multirow{3}{*}{\multicolumn{3}{|c|}{$\begin{array}{c}2.89(19,4871), p<0.001 \\
0.086 \\
784\end{array}$}} \\
\hline$R^{2}$ & & & \\
\hline$N$ & & & \\
\hline
\end{tabular}

Note. Entries are ordinary least-squares regression coefficients. Survey weights are applied; estimation was for the Catholic subsample $(n=784)$ but the full number of observations was $N=4,890$. 
Table A14: Predictors of Evaluations of Pope Francis Among Catholics, 2015 Pew (Ordinal Logit)

\begin{tabular}{|c|c|c|c|}
\hline \multirow[b]{2}{*}{ Predictor } & \multicolumn{3}{|c|}{2015 Pew } \\
\hline & \multicolumn{3}{|c|}{$C I$} \\
\hline Age & 0.34 & {$[-0.29,0.98]$} & $>0.250$ \\
\hline Income & -0.53 & {$[-1.14,0.08]$} & 0.091 \\
\hline White (1 = yes) & 0.32 & {$[-0.25,0.90]$} & $>0.250$ \\
\hline Latino $(1=$ yes $)$ & 0.38 & {$[-0.26,1.02]$} & 0.241 \\
\hline Education & 0.49 & {$[-0.16,1.13]$} & 0.139 \\
\hline Male $(1=$ yes $)$ & -0.07 & {$[-0.42,0.27]$} & $>0.250$ \\
\hline Religiosity & 2.00 & {$[0.98,3.02]$} & $<0.001$ \\
\hline Ideology & -0.15 & {$[-0.91,0.62]$} & $>0.250$ \\
\hline Doctrinal Conservatism & -0.62 & {$[-1.22,-0.01]$} & 0.047 \\
\hline Receive Sacraments & -0.18 & {$[-0.58,0.23]$} & $>0.250$ \\
\hline Believe Resurrection & -0.11 & {$[-0.56,0.34]$} & $>0.250$ \\
\hline Help Poor and Needy & 0.59 & {$[0.06,1.12]$} & 0.030 \\
\hline Belong to Parish & 0.05 & {$[-0.40,0.49]$} & $>0.250$ \\
\hline Oppose Abortion & 0.07 & {$[-0.18,0.32]$} & $>0.250$ \\
\hline Open to Children & 0.16 & {$[-0.17,0.49]$} & $>0.250$ \\
\hline Address Climate Change & -0.09 & {$[-0.37,0.18]$} & $>0.250$ \\
\hline Devotion to Mary & 0.29 & {$[-0.10,0.69]$} & 0.149 \\
\hline Relationship with Christ & 0.16 & {$[-0.43,0.75]$} & $>0.250$ \\
\hline Celebrate Feast Days & 0.12 & {$[-0.35,0.58]$} & $>0.250$ \\
\hline Cut 1 & -2.45 & {$[-3.78,-1.13]$} & \\
\hline Cut 2 & -1.17 & {$[-2.25,-0.11]$} & \\
\hline Cut 3 & 1.97 & {$[0.92,3.02]$} & \\
\hline$F(\mathrm{df})$ & \multirow{2}{*}{\multicolumn{3}{|c|}{$\begin{array}{c}2.72(19,4871), p<0.001 \\
784\end{array}$}} \\
\hline$N$ & & & \\
\hline
\end{tabular}

Note. Entries are ordinal-logit coefficients. Survey weights are applied; estimation was for the Catholic subsample $(n=784$ ) but the full number of observations was $N=4,890$. 
Pope Francis - 63

\section{References}

Ai, Chunrong, and Edward C. Norton. 2003. "Interaction Terms in Logit and Probit Models." Economics Letters 80: 123-129.

Karaca-Mandic, Pinar, Edward C. Norton, and Bryan Dowd. 2012. "Interaction Terms in Nonlinear Models." Health Services Research 47: 255-274. doi: 10.1111/j.1475-6773.2011.01314.x 